IZA DP No. 9384

Equality Concerns and the Limits of Self-Governance in Heterogeneous Populations

Lata Gangadharan

Nikos Nikiforakis

Marie Claire Villeval

September 2015 


\title{
Equality Concerns and the Limits of Self-Governance in Heterogeneous Populations
}

\author{
Lata Gangadharan \\ Monash University \\ Nikos Nikiforakis \\ New York University Abu Dhabi \\ Marie Claire Villeval \\ Université de Lyon, CNRS, GATE, \\ IZA and University of Innsbruck
}

\section{Discussion Paper No. 9384 \\ September 2015}

\author{
IZA \\ P.O. Box 7240 \\ 53072 Bonn \\ Germany \\ Phone: +49-228-3894-0 \\ Fax: +49-228-3894-180 \\ E-mail: iza@iza.org
}

Any opinions expressed here are those of the author(s) and not those of IZA. Research published in this series may include views on policy, but the institute itself takes no institutional policy positions. The IZA research network is committed to the IZA Guiding Principles of Research Integrity.

The Institute for the Study of Labor (IZA) in Bonn is a local and virtual international research center and a place of communication between science, politics and business. IZA is an independent nonprofit organization supported by Deutsche Post Foundation. The center is associated with the University of Bonn and offers a stimulating research environment through its international network, workshops and conferences, data service, project support, research visits and doctoral program. IZA engages in (i) original and internationally competitive research in all fields of labor economics, (ii) development of policy concepts, and (iii) dissemination of research results and concepts to the interested public.

IZA Discussion Papers often represent preliminary work and are circulated to encourage discussion. Citation of such a paper should account for its provisional character. A revised version may be available directly from the author. 


\section{ABSTRACT \\ Equality Concerns and the Limits of Self-Governance in Heterogeneous Populations*}

Mechanisms to overcome social dilemmas provide incentives to maximize efficiency. However, often - such as when agents are heterogeneous - there is a trade-off between efficiency and equality. Agents' concerns for equality in such instances can limit the ability of mechanisms to promote efficiency. We provide evidence for this from a public good experiment using a simple mechanism which allows individuals to communicate periodically with other group members and reward them for their actions. We show that, in homogeneous populations - where there is no tension between efficiency and equality - the mechanism permits group to obtain maximum efficiency. This is not the case in heterogeneous populations where individuals derive different benefits from cooperation. Although almost all heterogeneous groups agree to follow specific contribution rules with positive contributions, most of them either prioritize equality over efficiency or strike a compromise between the two. These findings suggest that equality concerns can impose limits on the ability of heterogeneous populations to reach efficient outcomes through self-governance.

JEL Classification: $\quad$ C92, H41, D74

Keywords: communication, rewards, cooperation, normative conflict, heterogeneity

Corresponding author:

Marie Claire Villeval

CNRS, GATE Lyon St Etienne

93, Chemin des Mouilles

F-69130, Ecully

France

E-mail: villeval@gate.cnrs.fr

\footnotetext{
* We are grateful to R. Cautain and Q. Thévenet for programming the experiment and to Z. Dai, J. Benistant and R. Suchon for valuable research assistance. We also thank participants at the "Social Norms and Institutions" conference in Ascona, Switzerland, the workshop on "Cooperation, Cultural Aspects and Norms" at the Hebrew University of Jerusalem, the Florida State University Entrepreneurship Experimental Workshop in Tampa, the ASFEE conference in Paris, the AFSEE conference in Rennes, and in seminars at New York University in Abu Dhabi, Queensland University of Technology in Brisbane and at GATE, Lyon, for useful comments. This research has been supported by a grant of the French National Research Agency (ANR, EMCO program, HEIDI grant, ANR-11-EMCO-011-01) and funding from the Australian Cooperative Research Centre for Water Sensitive Cities (CRC grant number 20110044). It was performed within the framework of the LABEX CORTEX (ANR-11-LABX-0042) of Université de Lyon, within the program Investissements d'Avenir (ANR-11-IDEX-007) operated by the French National Research Agency.
} 


\section{Introduction}

Social dilemmas are a topic of continuing interest among economists because of the tension between private and social interest. If this tension is not resolved, outcomes are likely to be inefficient (e.g., Samuelson, 1954). Accordingly, a large array of mechanisms has been proposed to provide incentives for individuals to act in accordance with the social interest (e.g., Laffont, 1987; Myerson, 2008). By 'social interest' most economists mean efficiency; efficiency is the ultimate normative criterion for evaluating the performance of a given mechanism. In many instances in daily life, however, efficiency is at odds with another normatively appealing rule: equality (e.g., Okun, 1975; Browning and Johnson, 1984). If individuals care strongly about equality as some evidence suggests (e.g., Cooper and Kagel, forthcoming), standard mechanisms may be less effective in promoting cooperation. Despite decades of research on social dilemmas, surprisingly little is known about how the tension between efficiency and equality is resolved in practice.

This paper presents the results from a laboratory experiment designed to address the following question: can equality concerns undermine the ability of a mechanism to promote efficiency when they are at odds with concerns for efficiency? The game we use as a testing ground is a variant of the voluntary contribution mechanism for public good provision. Our simple mechanism involves the use of communication and rewards at regular intervals. Based on past evidence, we have strong reasons to expect this mechanism will help groups maximize efficiency when there is no conflict with equality. We hypothesize that the 'normative conflict' between equality and efficiency will undermine the efficacy of the mechanism and result in reduced efficiency. ${ }^{1}$

The tension between efficiency and equality arises naturally in many instances such as when individuals derive different benefits from the provision of a public good (e.g., Chen and Plott, 1996; Nikiforakis et al. 2012; Reuben and Riedl, 2013). To address our research question, we compare treatments with homogeneous and heterogeneous populations. Group members in the experiment are all given the same endowment and must decide how much of it to contribute to a public account. Contributing to the public account generates a positive externality to all other group members and increases group earnings - a measure of group welfare - but each group member has a dominant strategy to keep all the money for him or herself. In half of our treatments, we assign higher returns

\footnotetext{
${ }^{1}$ A normative conflict is said to arise when multiple normatively appealing rules about how one ought to behave in a given situation coexist and prescribe different actions. For this to happen, these rules must have some properties that appeal to a large fraction of individuals. Considerable evidence suggests that equality and efficiency are such rules. For more general discussions on the topic, see Nikiforakis et al. (2012), Reuben and Riedl (2013).
} 
from the public account to some group members than their peers, based on their relative performance in a previous real-effort task. The heterogeneous returns create a stark trade-off between efficiency and equality: when efficiency is maximized, so is the inequality in the earnings of the different players' types. In the remaining treatments, all group members receive the same benefit from the public account. The homogeneity of groups implies that maximizing efficiency simultaneously leads to equality in earnings.

We chose a simple mechanism for our purposes. In the literature, the mechanisms designed to support cooperation differ greatly. On one end of the spectrum are centralized mechanisms with clearly defined incentives for performance (e.g., Groves and Ledyard, 1977). These are often complex and sometimes difficult to implement in practice (e.g., Laffont, 1987; Jackson and Moulin, 1992). ${ }^{2}$ On the other end are simple, decentralized mechanisms, without well-defined incentives, which rely on peer-monitoring and peer-provided incentives such as punishment (e.g., Fehr and Gächter, 2000; Masclet et al. 2003; Nikiforakis, 2008) and rewards (Rockenbach and Milinski, 2006; Sefton et al., 2007; Rand et al., 2009), and which are fairly easy to implement.

Our mechanism invites group members periodically to a forum and gives them the opportunity to communicate. Communication is anonymous, free form, and non-binding and is expected to assist groups in reaching a consensus about which contribution rule to adopt (e.g., Young, 1998). Non-binding communication has been found to unfailingly increase cooperation rates in social dilemmas (Ledyard, 1995; Sally, 1995; Zelmer, 2003; Chaudhuri, 2011). The efficacy of nonbinding communication is remarkable not only because it is observed in environments where communication does not affect equilibrium predictions, but also because of the large size of the effect (see next section). Apart from communicating in regular intervals, our mechanism allows individuals to reward group members for past contributions. In addition, rewards can be used to reduce inequality and thus alleviate the normative conflict by assigning greater rewards to lowreturn group members. In other words, our mechanism enables heterogeneous groups to reach an

\footnotetext{
${ }^{2}$ Jackson and Moulin (1992, p. 126) write: "The general results are technically impressive, but generally impractical for producing plausible mechanisms". Laffont $(1987$, p. 567) similarly writes: “... any real application will be made with methods which are crude approximations to the mechanisms obtained here ... considerations such as simplicity and stability to encourage trust, goodwill and cooperation, will have to be taken into account." More recently less complex, centralized mechanisms have been developed, e.g., Andreoni and Gee (2012), Falkinger (1996) and Varian (1994).
} 
agreement to maximize efficiency by cooperating fully, and minimize inequality through rewards. ${ }^{3}$ For this reason, we believe our experiment offers a challenging test for our hypothesis. ${ }^{4}$

All preceding studies allowing non-binding communication (or rewards) in social dilemmas used groups in which agents derived the same benefit from cooperation (see Ledyard, 1995; Sally, 1995; Zelmer, 2003; Chaudhuri, 2011). This homogeneity may therefore be partly responsible for the efficacy of communication. Field evidence suggests that communication may be less effective in heterogeneous populations. The most notable example may be the talks for an international agreement to reduce greenhouse gas emissions. After years of deliberations, several countries declined to ratify the Kyoto Protocol. The agreement itself failed to curb the growth of global emissions (World Bank, 2010) that continue to increase at an accelerating pace (Guardian, 2014). The 2009 conference in Copenhagen also failed to find a replacement agreement for Kyoto (Guardian, 2013). Different accounts for the failure of the climate-change talks suggest that normative conflict may have been a contributing factor. Developing countries argued in favor of relative reductions in emissions, emphasizing the smaller size of their economies and their historically lower rate of emissions. Rich, developed countries, on the other hand, reasoned that some of world's largest emitters are developing countries and argued in favor of absolute emission reductions (World Bank, 2010, p. 235). ${ }^{5}$

The results from our experiment demonstrate the importance of taking concerns for inequality into account when trying to promote efficiency in social dilemmas with heterogeneous populations. While communication has a positive effect on cooperation rates and group earnings in both homogeneous and heterogeneous populations, in line with our hypothesis, the size of the effect is substantially smaller in the latter case where there is normative conflict. In particular, communication increases cooperation rates by $265 \%$ in homogeneous groups, but only by $101.15 \%$ in heterogeneous groups. Group earnings increase by $80.84 \%$ in homogeneous groups, but by

\footnotetext{
${ }^{3}$ Formally, the opportunity to reward implies that an agreement in which all members contribute fully is not only Pareto efficient, but also Kaldor-Hicks efficient. An outcome is said to be Kaldor-Hicks efficient if those that are made better off could potentially compensate those worse off. The compensation does not have to occur.

${ }^{4}$ Rewards in our experiment can be used for different purposes such as rewarding high contributors irrespective of their type, increasing others' earnings without any regard for individual contributions and earning equality, or engaging in parochial behavior by rewarding participants of the same type. Rewards can also be used to establish a 'rewardexchange' relationship with other group members. Thus it is far from obvious that rewards will be used to alleviate the tension that arises from heterogeneity in returns from the public good in the absence of communication. To that end, we also explore behavior in control treatments, with reward but no communication opportunities.

${ }^{5}$ Another recent example involves the talks to overcome the debt crisis in Greece affecting the entire Eurozone. Throughout the five-year negotiation period, repeated appeals to fairness from both sides of the negotiation and to the need for structural reforms improving efficiency have led to tensions and costly delays.
} 
$46.26 \%$ in heterogeneous groups. This result is somewhat surprising given participants' ability to reward each other. Less than a quarter of all heterogeneous groups reach the fully efficient outcome when our mechanism is available, relative to $100 \%$ of the homogeneous groups. The lower efficacy of our mechanism in heterogeneous populations is not the result of an inability on the part of group members to agree on a given strategy (all but one of the groups reach stable agreements about which contribution rule to follow), but due to a preference for equality. Interestingly, rewards are assigned mostly equally to members irrespective of the contribution rule adopted or the returns obtained from the public good. Taken together, our results illustrate the importance of equality as a normative criterion and how the efficacy of communication is reduced in the presence of normative conflict.

The paper proceeds as follows. Section 2 introduces our experiment. This section starts with a discussion of earlier studies informing our design, and then presents details about the experiment, and the experimental procedures. In Section 3 we present our empirical findings. Section 4 concludes.

\section{The experiment}

\subsection{Related literature}

Our experimental design builds on earlier studies that have used laboratory experiments to investigate the impact of either communication or normative conflict on cooperation in social dilemmas. A large experimental literature has shown that, when individuals derive the same benefits from cooperation, communication has a positive effect on cooperation and often leads to maximal contributions (e.g., Ostrom et al., 1992; Brosig et al., 2003; Bochet et al. 2006; Bochet and Putterman, 2009; Janssen et al., 2010; Cason and Gangadharan, 2014). ${ }^{6}$ Overall, the size of the effect - the largest of any other single factor in social dilemmas (such as marginal per capita return, peer punishment and fixed group matching) according to the meta-analyses of Sally (1995) on prisoners' dilemma experiments and of Zelmer (2003) on public good games - is such that it has led some scholars to state that "self-governance is possible" (e.g., Ostrom et al., 1992; Janssen et al., 2010; Ostrom, 2012). ${ }^{7}$ However, none of these studies allow for communication between

\footnotetext{
${ }^{6}$ The form and timing of communication differs across studies. Early studies allowed for face-to-face communication, which took place once at the start of the experiment. More recently - with the advent of computer software - chatroom communication at different points in the experiment has become more common. An advantage of chatroom communication is that it can maintain subject anonymity. Bochet et al. (2006) show that periodic chatroom communication is as effective as face-to-face communication in promoting cooperation.

${ }^{7} \mathrm{We}$ do not disagree with the view that self-governance may be possible in some instances. Our study simply contributes to a literature investigating factors that may make self-governance more or less likely.
} 
agents deriving different benefits from cooperation. Given that the need for cooperation often emerges between heterogeneous agents in daily life, our study helps fill an important gap in the literature. Isaac and Walker (1988) is the only study we are aware of in which heterogeneous agents can communicate (but cannot assign rewards to each other). Unlike in our experiment, subjects receive different endowments but the same benefits from the public account. The authors find an 18-percent reduction in cooperation rates relative to a homogeneous treatment, but the sample size is small and it is unclear whether the reduction is statistically significant at any conventional level. ${ }^{8,9}$

Although several studies have explored the impact of heterogeneity on cooperation and efficiency in public good experiments, the vast majority of centralized mechanisms (e.g., Yamagishi, 1986; Falkinger et al., 2000; Andreoni and Gee, 2012) and decentralized mechanisms (e.g., Egas and Riedl, 2008; Fehr and Gächter, 2000) have utilized homogeneous groups. Therefore, we know little about how the tension between equality and efficiency affects the effectiveness of different mechanisms for promoting efficiency. Heterogeneity has been introduced in the voluntary contribution mechanism in a variety of ways. In some studies individuals are given different endowments from which to contribute (e.g., Buckley and Croson, 2006) in others they are given different returns from the public account (e.g., Fisher et al., 1995; Reuben and Riedl, 2009). In some studies the privilege to be a high 'income' participant is randomly assigned to participants (e.g., Reuben and Riedl, 2013) while in others it is earned in a separate task (e.g., Nikiforakis et al., 2012; Weng and Carlsson, 2015).

It is safe to say that the impact of heterogeneity overall is still unclear. For example, some studies examining the impact of heterogeneity in endowments find that it has a negative effect on cooperation (Cherry et al., 2005; Anderson et al., 2008), and some find it has a positive effect (Chan et al., 1996; Chan et al., 1999; Buckley and Croson, 2006; Reuben and Riedl, 2013). Similarly, evidence suggests that heterogeneity may operate differently in the presence and absence of mechanisms for promoting cooperation. For instance, in her meta-analysis Zelmer (2003) finds that, in the absence of such mechanism, heterogeneity in endowments has a stronger impact on cooperation than heterogeneity in the returns from the public account. The latter has a small

\footnotetext{
${ }^{8}$ Another potentially important difference is that in Isaac and Walker (1988) endowments are randomly allocated and not the result of past investments. Earning one's higher benefits from the public account in our experiment should reduce the appeal of equality and increase that of efficiency. This is an additional reason our experiment offers a difficult test for our research hypothesis.

${ }^{9}$ A recent paper by Dekel et al. (2015) examines communication with rewards and punishment in a public good experiment with heterogeneous returns in which one player in the group receives a negative return from the public account. Dekel et al. do not compare outcomes in heterogeneous and homogeneous groups.
} 
negative but statistically insignificant effect. In contrast, when mechanisms for enforcing cooperation exist, the opposite seems to hold. Nikiforakis et al. (2012) and Reuben and Riedl (2013) find that when individuals derive heterogeneous returns from a public account they are likely to disagree about which contribution rule should be adopted as a norm, and that heterogeneous returns from the public account limit substantially the efficacy of the punishment mechanism. Reuben and Riedl (2013) further show that, in such environments, normative conflict is stronger when individuals derive different benefits from a public account than when they have different endowments. ${ }^{10}$ Related to this, in a recent study, Weng and Carlsson (2015) show that peer punishment is equally effective in increasing contributions in groups with homogeneous and heterogeneous endowments. They also find that group identity has a positive effect in heterogeneous, but not in homogeneous groups.

In summary, it remains unclear from the literature whether the tension between equality and efficiency triggered by heterogeneous benefits from the public account can limit the welldocumented efficacy of communication. This seems especially true when the mechanism includes not only communication but also the possibility for individuals to use rewards to alleviate any earning inequalities arising from agents' heterogeneous preferences.

\subsection{The basic game}

In all treatments, subjects participate in a six-player linear public good game. Group assignment is fixed for the 20 periods of the game. Each period is divided into two stages. At the start of the first stage, each subject is given an endowment in experimental currency units (ECU 20, with ECU $10=$ Euro 0.25). Subjects have to allocate this endowment between a "private account" and a "public account". The earnings of group member $i$ at the end of the first stage are given by:

$$
\pi_{i}^{1}=\alpha\left(E-g_{i}\right)+\beta_{i} \sum_{j=1}^{n} g_{j}
$$

The parameters $E, \alpha$, and $\beta i$ denote, respectively, the endowment that subject $i$ has to allocate in the two accounts, the return to the endowment allocated to the private account, and the return to total allocations by the group towards the public account that, as explained below, may differ across

\footnotetext{
${ }^{10}$ Noussair and Tan (2011) find that when group members differ in the value of their contributions to other group members, groups fail to establish efficient punishment institutions. In a similar set up, Tan (2008) shows that punishment does not increase group earnings relative to a baseline treatment without punishment opportunities. However, neither of these two studies includes a treatment with homogeneous groups.
} 
subjects. The subject's decision variable in this stage is $g_{i}$, the amount of the endowment to contribute to the public good. This payoff function represents a social dilemma if and only if $\beta_{i}<\alpha<n \beta_{i}$, where $n$ is the number of members in the group. The first inequality shows that individual returns from the public good are lower than private returns, hence zero public good contribution is the dominant strategy Nash equilibrium. The second inequality implies that total returns received by the group from any public good allocation exceed the private returns; hence the social optimum is for every subject to contribute all resources to the public good. In our experiment, $\alpha=1$ and $\beta_{i}$ varies depending on the treatment.

At the start of the second stage subjects are informed about how much each group member has contributed to the public good, and $\beta_{j}$ (the returns from the public account) for all $j$. Subjects in this stage decide whether or not to reward other members in their group and increase their earnings by distributing reward points. ${ }^{11}$ Each point that individual $i$ assigns to group member $j$, $r_{i j}$, increases $j$ 's earnings by $1.5 \mathrm{ECU}$ and reduces those of the sender by $0.50 \mathrm{ECU}$. This $1: 3$ ratio is standard in public good games with rewards (or sanctions); it captures the idea that rewarding others creates positive externalities within a group. We expect that the 1:3 ratio will help alleviate the normative conflict between equality and efficiency as it is relatively cheap (e.g., vis-à-vis a 1:1 ratio) for group members to reduce inequality and provide incentives for others to contribute fully. The earnings of individual $i$ at the end of stage 2 are given by:

$$
\pi_{i}^{2}=\pi_{i}^{1}-0.5 \sum_{\substack{j=1 \\ j \neq i}}^{n} r_{i j}+1.5 \sum_{\substack{j=1 \\ j \neq i}}^{n} r_{j i}
$$

By assigning reward points, subjects can generate extra income from the experiment. To prevent subjects from (over)using the reward medium, we impose the following restrictions. Subject $i$ can assign a maximum of 20 points in total to all other group members, i.e., $\sum_{j} r_{i j} \leq 20 .{ }^{12}$ Under this limit, there is no constraint on the number of points $i$ can assign to a particular member. The second restriction is that no subject can benefit from receiving more than 20 ECU in rewards

\footnotetext{
${ }^{11}$ Reward points were referred to in the instructions as "addition points". To allow rewarding, at the start of each period group members are given a unique number between 1 and 6 . To limit the extent of reward-exchange over periods, the identifying numbers were randomly reassigned in each period.

${ }^{12}$ In daily life, the use of rewards is limited naturally by their cost which is likely to be convex and not linear. To keep experimental instructions simple and allow a more direct comparison of our results with those in past studies, we chose to keep the convention of a linear cost function and impose a restriction on the maximum number of points. As we discuss later in the paper, this restriction has advantages as it allows us to easily calculate the maximum possible earnings for participants.
} 
- the equivalent of their initial endowment - i.e., $1.5^{*} \sum_{j} r_{j i} \leq 20 \leftrightarrow \sum_{j} r_{j i} \leq 13.33$ points. The value of points exceeding $20 \mathrm{ECU}$ is not counted towards the final earnings, but the cost is incurred by the sender.

At the end of the period, each subject receives feedback on the individual number of points he received from each of his group members, together with each member's contribution, their identification number and their return rate from the public good $\left(\beta_{i}\right)$. The feedback also indicates the total cost of the points the subject assigned to others, the total benefit from the points that he received, and his net earnings in that period.

\subsection{Experimental treatments}

The experiment consists of four treatments using a $2 \times 2$ design. The treatments differ in two dimensions: the homogeneity of group members with respect to their individual returns from the public account, and the ability to communicate. We discuss each next.

Heterogeneity of returns from the public account: In two of the treatments, called "homogenous treatments", subjects benefit equally from the public good $\left(\beta_{i}=0.3\right.$, for all $\left.i\right)$. In the two other treatments, referred to as "heterogeneous treatments", half of the subjects in a group receive a higher return rate from the public account $\left(\beta_{i}=0.4\right)$, and the other half receive a lower return rate $\left(\beta_{i}=0.2\right)$. Thus the average return rate from the public account is the same as in the homogenous treatments.

Similar to Nikiforakis et al. (2012), to strengthen normative conflict the assignment of the return rates in the heterogeneous treatments depends on the relative performance of the subjects in a previous encryption task (like in Erkal et al., 2011, and Charness et al., 2014). For ten minutes, subjects are given a table assigning a number to each letter of the alphabet and are asked to use it to encrypt a number of words. To minimize selection effects, when performing this task, subjects are not provided with details about the public good game. They are only informed that: $(i)$ their relative performance will influence the maximum amount they can earn in the second part, and (ii) that they will be placed in groups of six, three of which will be "type A" and three of "type B", these two types receiving different returns from their decisions. The top $50 \%$ performers in the session are assigned to the type that obtains a higher return from the public good $(\beta=0.4)$ and the rest are assigned to the type that receives a lower return $(\beta=0.2)$. No other monetary incentives for performing the task are provided. At the end of the encryption task, subjects are informed about their type. No information about the exact number of words that other players encrypted is given until the end of the last period of the game. 
Communication: Our second treatment variable is communication. In the HOM-NC and the HET$\mathrm{NC}$ treatments (HOM for Homogenous, HET for Heterogeneous, and NC for No Communication), subjects are not able to communicate with others in their group. In contrast, in the HET-C and HOM-C treatments, subjects have the opportunity to communicate with the other five participants in their group in chat rooms on their computers. Our operationalization of communication is inspired by Bochet et al. (2006). Communication is permitted four times during the experiment: at the start of periods $1,6,11$ and 16 out of a total of 20 periods. The chat rooms are open for 5 minutes at the start of periods 1 and 6 and for 3 minutes at the start of periods 11 and $16 .{ }^{13}$ Messages are freeform. To increase the likelihood that communication helps groups overcome normative conflict and maximize efficiency, messages are visible to all group members. ${ }^{14}$ All participants are requested to follow some simple rules for this communication - they cannot identify themselves, they need to be civil to each other and cannot use any rude words - but apart from this, they can communicate about anything.

\subsection{The tradeoff between equality and efficiency}

In the homogeneous treatments, efficiency and equality are not at odds: when all group members contribute fully, efficiency is maximized and all earn the same amount. In the heterogeneous treatments, however, there is a tension between equality and efficiency. Keeping the option of rewarding others aside for a moment, for earnings to be equalized, high-return individuals have to contribute substantially more than their low-return peers. For our experimental parameters, high-return players must contribute four times as much as low-return players to equalize earnings prior to the reward stage. Efficiency, on the other hand, would prescribe that all group members contribute equally their entire endowment. However, maximizing efficiency in the absence of rewards implies maximizing inequality. In our setup a 1 ECU increase in each group member's contribution increases the earnings of high-return players by $1.4 \mathrm{ECU}$ and that of lowreturn players by $0.2 \mathrm{ECU}$. Thus, the overall difference increases by $1.2 \mathrm{ECU}$ with each additional ECU contributed to the public account. This implies that earning inequality is maximized when

\footnotetext{
${ }^{13}$ We varied the duration of communication as we expected group members to need less time to reach an agreement in the second half of the experiment, and also wanted to avoid participants getting bored waiting for the end of the communication time.

${ }^{14}$ In the HET-C treatment, communication took two forms. In one variant subjects could only send messages to everyone. In the second variant, subjects could also send 'private messages' to the group members with the same return as them. This was done to examine the robustness of our conclusions with regards to different types of communication. The figures (A1 for contributions and A2 for earnings) and Table A2 presented in Appendix 2 reveal that behavior is remarkably similar in the two variants (and always statistically insignificant). Hence, for brevity, we pool the data in our analysis.
} 
group earnings are maximized in which case $\pi_{H}-\pi_{L}=20 * 1.2=24 \mathrm{ECU}$, with $\pi_{L}=24 \mathrm{ECU}$ and $\pi_{H}$ $=48 \mathrm{ECU}$, where $\pi_{L}$ denotes the earnings of each low-return agent, and $\pi_{H}$ that of every high-return agent. Of course, rewards could be used in the second stage to redistribute earnings from the high return group members to the low return group members, so that the inequality associated with the priority given to efficiency can be mitigated.

\subsection{Procedures}

The experiment was conducted at GATE-LAB, Lyon, France. 246 subjects (of which $53.66 \%$ were female) were drawn from the undergraduate student population from local engineering, business and osteopathic medical schools and were invited to participate using ORSEE (Greiner, 2015). Subjects were only invited if they had not previously participated in any similar social dilemma experiment. No subject participated in more than one session. We ran 13 sessions in total. While subjects interacted anonymously in six-person fixed groups, multiple groups under the same treatment conditions participated simultaneously in the laboratory. Sessions were conducted on computers using z-Tree software (Fischbacher, 2007). Table 1 provides a summary of the treatments and the number of independent groups in each treatment. We collected more data in the heterogeneous treatments as we expected to observe more variability in decision making in these treatments.

Table 1 - Summary of experimental sessions

\begin{tabular}{lccccc}
\hline \hline Treatment & $\begin{array}{c}\text { Returns from } \\
\text { public account }\end{array}$ & Communication & Rewards & Participants & Groups \\
\hline HOM-NC & 0.3 & No & Yes & 48 & 8 \\
HOM-C & 0.3 & Yes & Yes & 36 & 6 \\
HET-NC & 0.2 or 0.4 & No & Yes & 60 & 10 \\
HET-C & 0.2 or 0.4 & Yes & Yes & 102 & $17^{(*)}$ \\
\hline Total & - & - & - & 246 & 41 \\
\hline \hline
\end{tabular}

Note: HOM-NC: Homogenous groups without communication; HOM-C: Homogenous groups with communication; HET-NC: Heterogeneous groups without communication; HET-C: Heterogeneous groups with communication. ${ }^{*}$ Het-C includes 48 participants (8 groups) who had the possibility to send messages visible either to all group members or only to group members of the same type, and 54 participants (9 groups) whose messages were made visible to all group members systematically.

Upon arrival, subjects drew a tag from an opaque bag, which randomly assigned them to a computer terminal. Sets of instructions were distributed at the beginning of each part and read aloud by the experimenter. The instructions and computer decision screens used neutral terminology, e.g., subjects "assigned" ECU to the public account instead of "contributing" to it; they received 
and assigned "addition" points, not "reward" points. Subjects answered a few control questions after reading the instructions to ensure that they understood the instructions and the process of decision-making. The instructions for the HET-C treatment are available in Appendix 1 (the instructions for the other treatments are available upon request). After the experiment, subjects filled out a survey intended to collect information about demographic characteristics and attitudes towards cooperation and rewarding others.

Subjects' earnings were the sum of their payoffs in the 20 periods in ECU which were then converted to Euros at the end of the session. Subjects earned 22.93 Euro on average, including a show-up fee of 5 Euro. Payments were made individually in cash and in private in a separate room by a secretary who was not aware of the content of the experiment (this was made common knowledge in the instructions). Including the instructions and payment distribution time, sessions lasted between 90 and 120 minutes.

\section{Experimental Results}

The presentation of the results is divided into two parts. In the first part, we present our main findings on how the normative conflict between equality and efficiency affects the efficacy of our mechanism in promoting cooperation and efficiency. In the second part, we explore the different contribution rules groups adopt and analyze the content of communication.

\subsection{Cooperation and efficiency}

Figures 1 and 2 present respectively the evolution of contributions and earnings across treatments. Table 2 presents summary statistics on contributions and earnings in the various treatments, along with the results from non-parametric tests. We proceed to state our main results and provide support for them.

Result 1: Communication has a positive impact on contribution levels in all treatments, but the size of the effect in heterogeneous groups is only $38.17 \%$ of that in homogeneous groups.

SUPPORT: As can be seen in Figure 1 and Table 2, in the absence of communication, although group members could reward high contributors, average contributions unravel and are similar in homogeneous (HOM-NC: $\bar{c}=5.37$ ) and heterogeneous groups (HET-NC: $\bar{c}=6.97$ ). Communication increases contributions in both homogeneous (HOM-C) and heterogeneous groups (HET-C), but its relative efficacy appears to be considerably limited in the presence of normative conflict: homogeneous groups contribute on average $97.85 \%$ of the maximum $(=19.57 / 20)$, which amounts to a $265 \%$ increase relative to contribution levels in HOM-NC. A Mann-Whitney test at 
the group level using the average contribution across periods as an independent observation indicates that the difference is statistically significant $(p=0.002)$. Heterogeneous groups on the other hand contribute on average $70.10 \%$ of the maximum when they can communicate $(=14.02 / 20)$ - an increase of $101.15 \%$ relative to contributions in HET-NC (Mann-Whitney, $p<0.001)$. Therefore, the increase in contributions due to the introduction of communication opportunities in heterogeneous groups is $38.17 \%$ of that in homogeneous groups. A Mann-Whitney test indicates that contributions are not significantly different in HOM-NC and HET-NC ( $p=0.374)$, but are significantly lower in HET-C than in HOM-C $(p<0.001)$.

Figure 1 - Mean contributions across treatments

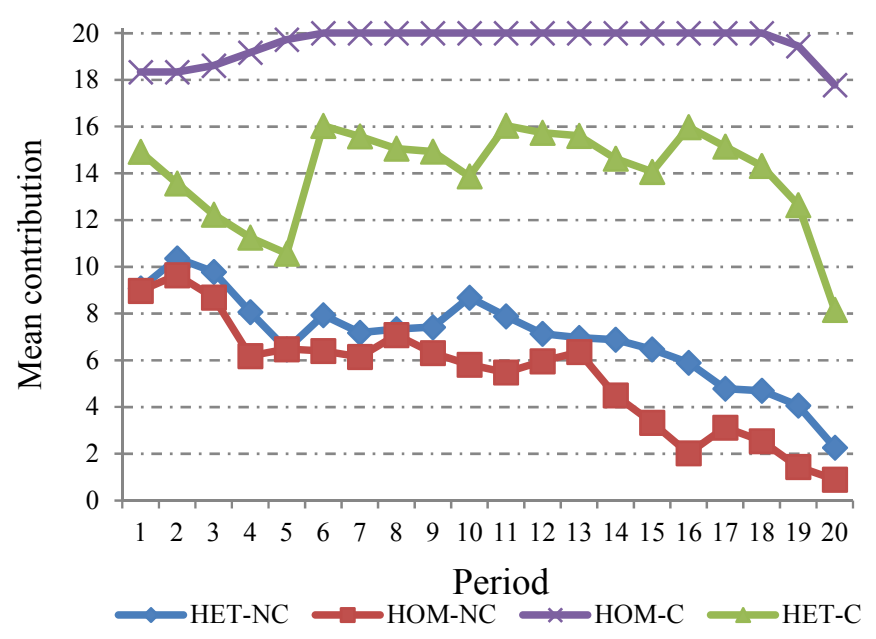

It is interesting to note that the effect of our mechanism on contributions in Figure 1, apart from being weaker in heterogeneous groups, also appears to be less stable: after an increase in periods of communication (i.e., periods $1,6,11$, and 16), contributions decline in the following periods. A linear regression with individual-level random effects and clustering at the group level shows that, on average, contributions in HET-C are 2.19 ECU higher in communication periods $(p<0.001)$ compared to non-communication periods. A similar regression for the HOM-C treatment also finds a significant immediate effect of communication on contributions compared to periods without communication, but it is much weaker (0.101 ECU, $p=0.004$ ). We explore the causes of this instability in heterogeneous groups in the following subsection. Next, we present our second main result regarding earnings in the experiment. This is a distinct question from how communication impacts on cooperation as subjects could reward each other. 
Recall from section 2.2 that we imposed restrictions on the number of reward points that can be assigned to prevent the exploitation of the reward medium by participants. A benefit of such restrictions is that it allows us to calculate the maximum earnings when all contribute fully to the public account and compare them to the actual earnings from the experiment, as a measure of efficiency. In homogeneous treatments, group earnings are maximized when $g_{i}=g_{-i}=20, r_{i j}=$ 13.33 (which implies a cost of $6.67 \mathrm{ECU}$ ) and $\sum_{j} r_{j i}=13.33$ (which implies a gain of $20 \mathrm{ECU}$ ), assuming for simplicity that subjects could choose an integer number of reward points. These numbers imply that the maximum individual earnings in the experiment from both stages are $36-$ $6.67+20=49.33$ ECU. In heterogeneous treatments, on average maximum earnings are the same as in homogeneous treatments, but given the different returns from the public account, when all contribute fully to the public account and assign the 'optimal' number of points (13.33), high-return subjects can earn up to $61.33 \mathrm{ECU}(=48-6.67+20)$, and low-return subjects can earn up to 37.33 $\operatorname{ECU}(=24-6.67+20)$.

Table 2 - Summary statistics on contributions and final earnings

\begin{tabular}{lccccc}
\hline \hline \multirow{2}{*}{ Treatments } & \multirow{4}{4}{ Heterogeneous } \\
\cline { 3 - 6 } & Homogeneous & $\begin{array}{c}\text { All } \\
\text { subjects }\end{array}$ & $\begin{array}{c}\text { High-return } \\
\text { Subjects }\end{array}$ & $\begin{array}{c}\text { Low-return } \\
\text { subjects }\end{array}$ & Ratio H/L \\
\hline Mean contributions & & & & & \\
Without communication (1) & $5.37(6.99)$ & $6.97(7.43)^{\text {ns }}$ & $9.53(7.72)$ & $4.40(6.14)^{* *}$ & 2.17 \\
With communication (2) & $19.57(2.35)$ & $14.02(7.49)^{* * *}$ & $17.27(6.18)$ & $10.76(7.27)^{* * *}$ & 1.60 \\
(1) vs. (2) & $p=0.002$ & $p<0.001$ & $p<0.001$ & $p=0.003$ & \\
\hline Mean final earnings & & & & & \\
Without communication (3) & $25.63(6.46)$ & $27.02(7.20)^{\text {ns }}$ & $29.25(7.61)$ & $24.79(6.00)^{* * *}$ & 1.18 \\
With communication (4) & $46.35(4.33)$ & $39.52(11.04)^{* * *}$ & $44.66(11.00)$ & $34.38(8.37)^{* * *}$ & 1.30 \\
(3) vs. (4) & $p=0.002$ & $p<0.001$ & $p<0.001$ & $p<0.001$ & \\
\hline \hline
\end{tabular}

Note: Standard deviations in parentheses. Comparisons between conditions ((1) vs. (2) and (3) vs. (4)) report the $p$-values of Mann-Whitney tests in which each group averaged over all periods gives one independent observation. In column "All subjects", $* * *$ and ns indicate significance at the $1 \%$ level and no significance, respectively, in Mann-Whitney tests comparing the mean contribution and mean earnings, respectively, in heterogeneous and in homogeneous groups. In the column "Low-return subjects", *** and ** indicate significance at the $1 \%$ and $5 \%$ levels, respectively, in Wilcoxon tests comparing contributions and earnings relative to low-return vs. high-return subjects. 
Result 2: Communication has a positive impact on group earnings in all treatments, but the size of the effect in heterogeneous groups is only $57.22 \%$ of that in homogeneous groups.

SUPPORT: Figure 2 presents the evolution of earnings across treatments. On average, earnings are not significantly different, without communication, in homogeneous groups (HOM-NC: $\bar{\pi}_{\iota}^{2}=$ 25.63) and in heterogeneous groups (HET-NC: $\bar{\pi}_{\iota}^{2}=27.02$ ) (Mann-Whitney, $p=0.286$ ). Earnings are higher with communication, but again we observe that the relative efficacy of communication appears to be considerably weakened by the presence of normative conflict: an individual in a homogeneous group earns on average $46.35 \mathrm{ECU}$, i.e., $94 \%$ of the maximum. This amounts to an increase of $80.84 \%$ relative to HOM-NC, which is statistically significant (Mann-Whitney, $p=0.002$ ). In contrast, individuals in heterogeneous groups earn on average $39.52 \mathrm{ECU}$, i.e., $80.11 \%$ of the maximum. The increase in earnings relative to HET-NC is $46.26 \%$ and statistically significant (Mann-Whitney, $p<0.001$ ). However, it is only $57.22 \%$ of the increase in earnings due to communication in homogeneous treatments. A Mann-Whitney test indicates that earnings are significantly lower in HET-C than in HOM-C $(p<0.001)$.

Figure 2 - Mean earnings across treatments

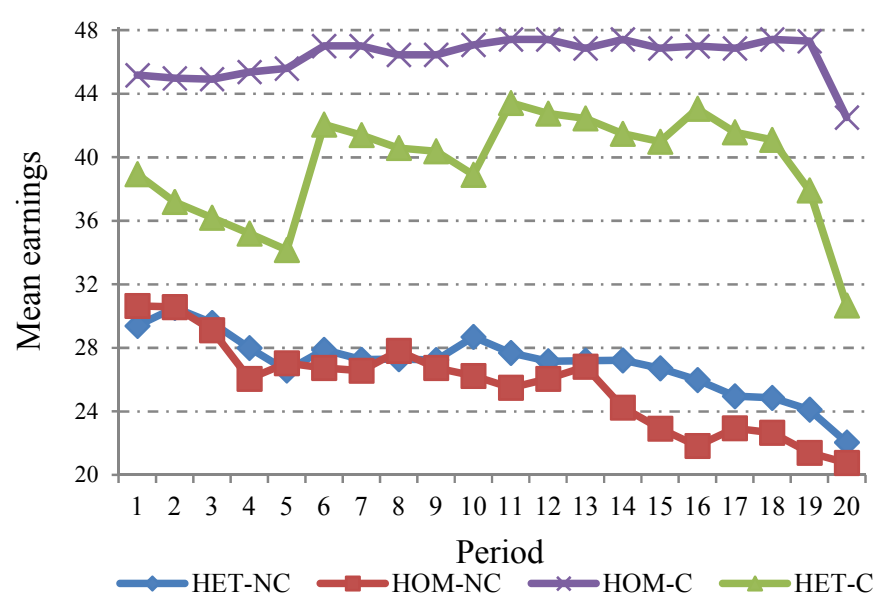

The fact that earnings are $94 \%$ of the maximum when homogeneous groups can communicate is quite extraordinary. Unlike previous experiments where individuals had to agree only on how much to contribute, subjects in HOM-C also had to agree on their rewarding strategies. The design (see section 2.2) allowed for overuse of rewards (when $13.33<\bar{r}_{i j} \leq 20$ ) and underuse (when $\bar{r}_{i j}$ $<13.33$ ). Finding the right balance between providing adequate incentives for cooperation and avoiding wasteful overuse of the reward medium is not simple and requires coordination amongst 
group members. We conclude this subsection by investigating the aggregate patterns concerning the receipt of rewards across treatments.

Result 3: Individuals in homogeneous groups receive on aggregate slightly more reward points than is optimal when they can communicate. In contrast, individuals in heterogeneous groups receive slightly less than the optimal amount of reward. Consequently fewer reward points are received in heterogeneous versus homogenous groups.

SUPPORT: Table 3 presents summary statistics concerning reward points received across treatments. Clearly, communication increases the number of reward points received substantially in both homogeneous groups $\left(\bar{r}_{i j}[\mathrm{HOM}-\mathrm{NC}]=1.34\right.$ vs. $\bar{r}_{i j}[\mathrm{HOM}-\mathrm{C}]=16.97$; Mann-Whitney, $p=0.002)$, and heterogeneous groups $\left(\bar{r}_{i j}[\mathrm{HET}-\mathrm{NC}]=2.74\right.$ vs. $\left.\bar{r}_{i j}[\mathrm{HET}-\mathrm{C}]=11.24 ; p<0.001\right)$. More interestingly, the number of reward points is significantly higher than the optimal number of points $\left(\bar{r}_{i j}=13.33\right)$ in HOM-C (Wilcoxon sign rank, $p=0.046$ ), while it is slightly (albeit significantly) lower in HET-C (Wilcoxon sign rank, $p=0.024$ ). The number of reward points in HET-C is significantly lower than in HOM-C (Mann-Whitney, $p=0.003$ ). For completeness, we report that the difference in reward points in HET-NC and HOM-NC does not reach a conventional level of statistical significance (Mann Whitney, $p=0.197$ ).

Table 3 - Summary statistics on the receipt of reward points

\begin{tabular}{|c|c|c|c|c|}
\hline \multirow{2}{*}{ Treatments } & \multirow{2}{*}{ Homogeneous } & \multicolumn{3}{|c|}{ Heterogeneous } \\
\hline & & All subjects & High return subjects & Low return subjects \\
\hline $\begin{array}{l}\text { Without communication } \\
\text { (1) }\end{array}$ & $\begin{array}{c}1.34 \\
(2.32)\end{array}$ & $\begin{array}{l}2.74^{\mathrm{ns}} \\
(4.53)\end{array}$ & $\begin{array}{c}3.37 \\
(5.14)\end{array}$ & $\begin{array}{c}2.12^{\mathrm{ns}} \\
(3.72)\end{array}$ \\
\hline $\begin{array}{l}\text { With communication } \\
\text { (2) }\end{array}$ & $\begin{array}{l}16.97 \\
(4.53)\end{array}$ & $\begin{array}{l}11.24 * * * \\
(7.16)\end{array}$ & $\begin{array}{r}11.62 \\
(7.31)\end{array}$ & $\begin{array}{l}10.86^{\mathrm{ns}} \\
(6.99)\end{array}$ \\
\hline (1) vs. (2) & $p=0.002$ & $p<0.001$ & $p<0.001$ & $p<0.001$ \\
\hline
\end{tabular}

Notes: Entries are the mean number of reward points received. Standard deviations are in parentheses. Comparisons between conditions ((1) vs. (2) report the $p$-values of Mann-Whitney tests in which each group gives one independent observation. In column "All subjects", *** and ${ }^{\text {ns }}$ indicate significance at the $1 \%$ level and no significance, respectively, in Mann-Whitney tests comparing the mean number of reward points received in heterogeneous and in homogeneous groups. In column "Low return" ns indicates no significance in Wilcoxon tests comparing the mean number of points received by low-return and high-return subjects.

Result 3 provides two insights. The first is that the slight loss in efficiency relative to the maximum in HOM-C between periods 6 and 19 when they contribute their full endowment in the public account discussed in the support for Result 2 (see Figures 1 and 2) stems from the fact that 
more reward points are used than what is required for maximum efficiency. The second insight is that the inefficiency observed in heterogeneous groups is not only due to the inefficiently low levels of contribution, but also due to a relative underuse of rewards. In particular, the lower-than-optimal number of reward points in HET-C (11.24 vs. 13.33) translates into an efficiency loss of 2.09 ECU $\left(=[13.33-11.24]^{*}[1.5-0.5]\right)$. Recall that earnings in HET-C were on average 9.81 ECU lower than the maximum earnings $(49.33$ - 39.52). Therefore, the suboptimal number of reward points accounts for $21.3 \%$ of the loss in efficiency, whereas the remaining $79.7 \%$ is due to the relatively low levels of contribution.

In order to better understand why our mechanism based on communication and rewards is unable to facilitate full cooperation in heterogeneous groups, we turn our attention to the behavior of high and low-return players in heterogeneous treatments.

\subsection{Contribution norms in HET-C}

Having found support for our hypothesis that the normative conflict in heterogeneous groups undermines the efficacy of communication, we turn our attention to individual groups. We are interested in understanding why normative conflict has this effect. Is it that groups fail to agree on a contribution rule or is it that they adopt rules which favor equality over efficiency? To answer this question, we focus on behavior in treatment HET-C since in HET-NC, it is clear that contribution unravels over time, whereas in HOM-C all groups agree to contribute fully for almost the entire experiment.

Table 4 presents median contributions, reward points and profits from periods 6 to period 19 (i.e., from the second communication round to the end of the experiment, excluding the first block of periods where subjects learn the game and excluding the last period to avoid end-game effects). The use of medians provides a clearer picture of the contribution rules favored by groups as it is less sensitive to outliers.

Groups can be classified into one of three categories with regards to the contribution rule they adopted: groups that adopted the contribution rule favoring equality over efficiency; groups that adopted the rule favoring efficiency over equality; and groups that struck a compromise between these two rules. The classification of groups in Table 4 and the conclusions derived from it are robust to using medians for periods 11 to 19 , or periods 16 to 19 .

Result 4: Most heterogeneous groups manage to adopt stable contribution rules with positive contributions to the public account. 
SUPPORT: As can be seen in Table 4, 15 of the 17 groups (i.e., 88.2\%) reach a stable agreement about which contribution rule to follow. This can be seen in the fifth column that presents the "Contribution ratio trend". The contribution ratio is the ratio of contributions by high return subjects to low return subjects; the "trend" is the coefficient from an OLS regression with the contribution ratio as the dependent variable and period as the only independent variable. Except group 1 which experienced an increase in the contribution ratio between periods 6 and 19, the contribution ratio did not change significantly over time in any of the other groups. ${ }^{15}$ Although the contribution ratio remained constant over time in group 12, contributions collapsed to 0 for all group members after period 14 (with the exception of period 16). ${ }^{16}$ The fact that most groups manage to adopt stable contribution rules through communication is in stark contrast to the behavior observed in Nikiforakis et al. (2012) where communication was not allowed. Therefore, we conclude that overall communication helps heterogeneous groups overcome normative conflict and establish group norms regarding individual contributions.

Result 5: Only a small minority of heterogeneous groups select the efficient contribution rule. Most groups choose either a contribution rule that strictly prioritizes equality over efficiency, or a rule that strikes a compromise between equality and efficiency concerns.

SUPPORT: As can be seen in Table 4, only four of the 17 groups (i.e., 23.5\%) reached a stable agreement in which high and low-return group members contributed their entire endowment. Six of the 17 groups (i.e., 35.3\%) chose the contribution rule that maximizes group earnings but conditional on high and low-return members having equal (first-stage) earnings, i.e., $c_{H}=20$ and $c_{L}=5$. That is, these groups prioritize equality over efficiency. Six more groups eventually settled on rules satisfying $c_{H}=\alpha c_{L}$, where $1<\alpha<4$. These rules are in line with Young (1998) who argues that in cases of normative conflict individuals would eventually reach a compromise. It is also worth noting that a contribution ratio of two - observed in three groups - is in line with the "proportionality rule" according to which group members should contribute in proportion to their relative benefit from the public account (Reuben and Riedl, 2013). In other words, of the 16 groups that adopted and maintained a contribution rule with positive contributions (i.e., all groups except group 12), 12 groups (i.e., 75\%) agree on a rule reflecting a concern for equality.

\footnotetext{
${ }^{15}$ In periods $16-19$, in group 1 , the median contribution of the high-return players increased to 20 while that of low types remained unchanged at 15 . This implies that, all together, 16 out of 17 groups (94.1\%) adopted rules which prevented the decay of cooperation.

${ }^{16}$ Group 12 is solely responsible for the downward trend observed in contributions in Figure 1 in periods following communication. In none of the other groups do contributions decline significantly following communication.
} 
Results 4 and 5 help explain the main findings in the previous section, i.e., why efficiency is lower in heterogeneous groups: it is not that the tension between efficiency and equality is unresolved by our simple mechanism. The reason cooperation rates and efficiency are lower in heterogeneous groups in HET-C compared to HOM-C is because $75 \%$ of the groups in HET-C showed a concern for reducing inequality in earnings. This concern places a limit to the ability of our mechanism to increase efficiency up to its maximum level. It is important to note that an analysis of the content of communication, as well as the responses to a post-experiment survey at the group level fully supports our classification of groups and the conclusions above. This analysis can be found in Table A2 in Appendix 3. We conclude this section with an examination of rewarding behavior across groups adopting different contribution rules.

Result 6: Overall, rewards are not used to alleviate earning equalities. Low-return group members do not receive on average more reward points than high-return members.

SUPPORT: As can be seen in Table 3, for all periods, and in Table 4 for periods 6 to 19, on average, low and high-return subjects receive a similar amount of points. A Wilcoxon sign-rank test shows that the average number of reward points received by high-return subjects across all periods and groups is far from being significantly different from that of low-return subjects ( $p=0.981$, two-tailed). Even if we concentrate our attention on the 11 groups that did not adopt the equal-earnings rule, (the groups in which one would expect that low-return members would be rewarded more), the difference is small and far from being statistically significant (high: 12.6, low: $11.9 ; p=0.929)$. The assignment of reward points reflects the contribution rule in the group over time, regardless of the players' type. Interestingly, in groups that prioritize efficiency, high-return players tend to receive more rewards than low-return players, although the former already earn substantially more. However, we do not have sufficient number of observations to perform a meaningful non-parametric comparison. In "other groups" on average low types receive more reward points, but not significantly so $(p=0.203)$. The analysis of the content of communication shows that groups rarely discussed the idea of using rewards to compensate low return group members (see Appendix 3). 
Table 4 - Group-level analysis of contributions, rewards and earnings in the HET-C treatment

\begin{tabular}{|c|c|c|c|c|c|c|c|c|}
\hline $\begin{array}{l}\text { Group } \\
\text { number } \\
\text { (1) }\end{array}$ & $\begin{array}{l}\text { Contribution } \\
\text { high-return } \\
\text { (2) }\end{array}$ & $\begin{array}{l}\text { Contribution } \\
\text { low-return } \\
\text { (3) }\end{array}$ & $\begin{array}{l}\text { Contribution } \\
\text { ratio } \\
\text { (4) }\end{array}$ & $\begin{array}{l}\text { Contribution } \\
\text { ratio trend } \\
(5)^{+}\end{array}$ & $\begin{array}{c}\text { Reward received } \\
\text { by high-return } \\
\text { (6) }\end{array}$ & $\begin{array}{c}\text { Reward received } \\
\text { by low-return } \\
\text { (7) }\end{array}$ & $\begin{array}{c}\text { Earnings } \\
\text { high-return } \\
\text { (8) }\end{array}$ & $\begin{array}{c}\text { Earnings } \\
\text { low-return } \\
\text { (9) }\end{array}$ \\
\hline \multicolumn{9}{|c|}{ Equality-over-Efficiency Groups } \\
\hline 4 & 20 & 5 & 4 & -0.11 & 14 & 14 & 40 & 40 \\
\hline 5 & 20 & 5 & 4 & 0.00 & 12.5 & 12 & 40.5 & 40.5 \\
\hline 9 & 20 & 5 & 4 & 0.00 & 15 & 15 & 42.5 & 42.5 \\
\hline 11 & 20 & 5 & 4 & 0.00 & 20 & 20 & 40 & 40 \\
\hline 13 & 20 & 5 & 4 & 0.18 & 14 & 14 & 40 & 40 \\
\hline 14 & 20 & 5 & 4 & 0.00 & 13 & 13 & 43 & 43 \\
\hline \multicolumn{9}{|c|}{ Efficiency-over-Equality Groups } \\
\hline 3 & 20 & 20 & 1 & 0.00 & 18 & 6.5 & 60.3 & 30.3 \\
\hline 7 & 20 & 20 & 1 & 0.00 & 20 & 14 & 58 & 34.3 \\
\hline 10 & 20 & 20 & 1 & -0.01 & 10 & 10 & 58 & 34 \\
\hline 17 & 20 & 20 & 1 & 0.00 & 15 & 15 & 60.5 & 36.5 \\
\hline \multicolumn{9}{|c|}{ Other Groups } \\
\hline 1 & 15 & 15 & 1 & $0.03 * * *$ & 20 & 20 & 51 & 34.7 \\
\hline 2 & 20 & 10 & 2 & -0.01 & 9.5 & 5 & 42.3 & 33 \\
\hline 6 & 20 & 0 & - & 0.00 & 11 & 13 & 43.5 & 48.2 \\
\hline 8 & 20 & 10 & 2 & 0.00 & 11 & 11.5 & 46.5 & 36 \\
\hline $12^{\mathrm{a}}$ & 20 & 20 & 1 & 0.00 & 1.5 & 3.5 & 38.5 & 28 \\
\hline 15 & 20 & 15 & 1.33 & 0.00 & 10 & 16 & 50.5 & 40 \\
\hline 16 & 20 & 10 & 2 & -0.03 & 12 & 16 & 41.8 & 40 \\
\hline Average & 19.7 & 11.2 & 2.3 & 0.00 & 13.3 & 12.9 & 46.3 & 37.8 \\
\hline
\end{tabular}

Notes: Entries are medians from periods 6 to 19 . $^{\text {a }}$ In Group 12, although the contribution ratio does not change, cooperation collapses with all contributing 0 after period 14 (and except period 16). So it is not consistent with efficiency. ${ }^{+}$Coefficients from an OLS regression for periods 6 to 19 with the "contribution ratio" as the dependent variable and "period" the only independent variable. $* * * p<0.001 ; * * p<0.05 ; * p<0.1$ 


\section{Discussion}

In many instances when the need for cooperation arises, concerns for equality are at odds with efficiency. We presented evidence from a laboratory experiment investigating how such tension between equality and efficiency could affect the ability of groups to cooperate. The 'news' are both good and bad. All groups except one (16 out of 17; i.e., 94.1\%) managed to agree on specific contribution rules with positive contribution levels and follow them. This is a novel and promising finding which we did not anticipate. As Elster (1989) notes in a discussion of evidence from social psychology, individuals often try to select contribution rules as social norms in a self-serving manner. In line with this, Nikiforakis et al. (2012) found that high-return group members tried to enforce efficiency, while low-return group members tried to enforce equality in their groups. Our simple mechanism allowing groups to periodically communicate and reward members, enabled virtually all of them to reach stable cooperation agreements with positive contributions. This finding therefore supports the view that, at least in some instances, "self-governance is possible" (Ostrom et al., 1992). This is the good news.

The bad news is that concerns for equality appear to impose a limit on the efficacy of selfgovernance mechanisms: less than a quarter of groups ( 4 out of 17; i.e., $23.5 \%$ ) chose to follow the contribution rule that maximizes group earnings. This is the case despite the opportunity for groups to eradicate inequality through the use of rewards such that inequality is reduced or even eliminated. Why do individuals fail to use rewards in such manner when clearly they care about equality? This is a puzzle and indicates that more empirical work is needed in order to establish the limits of our conclusions and better understand how to effectively promote cooperation in heterogeneous populations. For one thing is clear from our experiment: although individuals appear to be far more able to cooperate than typically assumed by economists, the problem of cooperation is also more complex than simply aligning private and 'social' interests. The latter includes not only concerns for efficiency, but also for equality, and possibly other kinds of normatively appealing rules such as those for equity. ${ }^{17}$

The fact that fairness concerns influence which contribution rules groups adopt suggests numerous interesting avenues for future research. Most experimental work examining the efficacy of mechanisms for promoting cooperation and efficiency has considered the special case of homogeneous groups. In heterogeneous populations, in addition to overcoming free riding

\footnotetext{
${ }^{17}$ The principle of equity prescribes that one is compensated in proportion to his or her input. The real-effort stage in our experiment implies that equity is at odds with equality and makes the dominant role of the latter, even more striking.
} 
incentives, group members have to resolve the conflict between efficiency and inequality. Some mechanisms will be better at dealing with this normative conflict than others. For example, mechanisms that rely solely on coercion and peer punishment may be less effective (see e.g., Nikiforakis et al. 2012; Cason and Gangadharan, 2012; Cason and Gangadharan, 2014). Moreover, the efficacy of a given mechanism may depend on the type of heterogeneity (e.g., different returns to cooperation vs. different abilities to contribute), the extent of the heterogeneity (e.g., small vs. large differences) or the ability of individuals to opt out from mechanisms that lead to unequal outcomes (e.g., Chen and Plott, 1996). Therefore, it is important to test the performance of mechanisms also in heterogeneous and not only in homogeneous populations as is often the case.

Our results suggest that our simple mechanism - particularly the ability to communicate repeatedly with all parties involved - can help sustain cooperation even in heterogeneous populations. Some interesting questions for future research arise from our study. For example, how does the tension between equality and efficiency affect the institutions created to promote cooperation (e.g., Markussen et al. 2014; Sutter et al. 2010)? What if heterogeneity is multidimensional (e.g., different endowments, benefits from cooperation, past investments)? What happens if individuals are unsure about the preferences and circumstances of others? What happens when the size of groups increases and with it the costs of communication and monitoring? Are there other mechanisms that can promote cooperation in heterogeneous populations when communication is impossible? What would happen if the relative cost of assigning rewards would differ across subjects?

To conclude, saying "self-governance is possible" does not imply that interested parties will always manage to cooperate. Nor do we claim that our simple mechanism will always enable groups to reach mutually benefits agreements. The main message from our experiment is the following: in many instances in daily life, the predicament with cooperation may not be individuals' unwillingness to cooperate due to private incentives to free ride as often assumed (see our HOM$\mathrm{C}$ treatment), but their inability to reach an agreement that will simultaneously satisfy the fairness concerns of all individuals with their heterogeneous preferences. Given the widespread need for cooperation in the modern world (e.g., climate negotiations and the recent talks in the Eurozone) acknowledging the complexity of cooperation in heterogeneous populations and trying to understand how to engineer cooperation appears to be not only an interesting research topic, but also a topic of great practical significance. 


\section{References}

Anderson, L. R., J. M. Meller, Milyo, J. (2008). Inequality and public good provision: an experimental analysis. Journal of Socio-Economics 37 (3), 1010-1028.

Andreoni, J., Gee, L.K. (2012). Gun for hire: delegated enforcement and peer punishment in public goods provision. Journal of Public Economics 96 (11), 1036-1046.

Bochet, O., Page, T., Putterman, L. (2006). Communication and punishment in voluntary contribution experiments. Journal of Economic Behavior and Organization 60, 11-26.

Bochet O, Putterman L. (2009). Not just babble: A voluntary contribution experiment with iterative numerical messages. European Economic Review 3, 309-326.

Brosig, J., J. Weimann, Ockenfels, A. (2003). The effect of communication media on cooperation. German Economic Review 4(2), 217-241.

Browning, E.K., Johnson, W.R. (1984). The trade-off between equality and efficiency. Journal of Political Economy 92 (2), 175-203.

Buckley, E., Croson. R. (2006). Income and wealth heterogeneity in the voluntary provision of linear public goods. Journal of Public Economics 90(4-5), 935-955.

Cason, T., Gangadharan, L. (2013). Empowering neighbors versus imposing regulations: an experimental analysis of pollution reduction schemes. Journal of Environmental Economics and Management. 2013, 65, 469-484.

Cason, T., Gangadharan, L. (2014). Swords without covenants do not lead to self-governance, Journal of Theoretical Politics, 1-30.

Chan, K. S., Mestelman, S., Moir, R., Muller, R. A. (1996). The voluntary provision of public goods under varying income distributions. The Canadian Journal of Economics 29(1), 54-69.

Chan, K. S., Mestelman, S., Moir, R., Muller, R. A. (1999). Heterogeneity and the voluntary provision of public goods. Experimental Economics 2(1), 5-30.

Chen, Y., Plott, C. R. (1996). The Groves-Ledyard mechanism: An experimental study of institutional design. Journal of Public Economics 59 (3), 335-364.

Cherry, T., S. Kroll, Shogren, J. (2005). The impact of endowment heterogeneity and origin on public good contributions: evidence from the lab. Journal of Economic Behaviour and Organization 57, 357-365.

Charness, G., Masclet, D., Villeval M.C. (2014). The dark side of competition for status. Management Science 60(1), 38-55.

Cooper, D. J., Kagel, J. H. (Forthcoming). Other regarding preferences: A selective survey of experimental results, forthcoming in Handbook of Experimental Economics Vol. 2.

Dekel, S., Fischer, S., Zultan, R. (2015). Punishment and reward institutions with harmed minorities. Ben-Gurion University of the Negev, Department of Economics.

Egas, M., Riedl, A. (2008). The economics of altruistic punishment and the maintenance of cooperation. Proceedings of the Royal Society B - Biological Sciences 275 (1637), 871-878.

Erkal, N., Gangadharan, L., Nikiforakis, N. (2011). Relative Earnings and Giving in a Real Effort Experiment. American Economic Review 101(7): 3330-3348. 
Falkinger, J. (1996). Efficient Private Provision of Public Goods by Rewarding Deviations from Average. Journal of Public Economics 62(3), 413-422.

Falkinger, J., Fehr, E., Gächter, S., Winter-Ebmer, R. (2000). A Simple Mechanism for the Efficient Provision of Public Goods: Experimental Evidence. American Economic Review 90(1), 247-264.

Fehr, E., Gächter, S. (2000). Cooperation and Punishment in Public Goods Experiments. American Economic Review 90 (4), 980-994.

Fischbacher, U. (2007). z-Tree: Zurich toolbox for ready-made economic experiments, Experimental Economics 10(2), 171-178.

Fisher, J., R. Isaac, J. Shatzberg, Walker, J. 1995. Heterogeneous demand for public goods: behavior in the voluntary contributions mechanism. Public Choice 85(3), 249-266.

Greiner, B. (2015). Subject Pool Recruitment Procedures: Organizing Experiments with ORSEE. Journal of the Economic Science Association 1, 114-125.

Groves, T., Ledyard, J.O. (1977). Optimal allocation of public goods: A solution to the 'free-rider' problem, Econometrica 4, 783-809.

Isaac, R., Walker, J. (1988). Communication and free-riding behaviour: the voluntary contribution mechanism. Economic Inquiry 26, 585-608.

Jackson, M., Moulin, H. (1992). Implementing a public project and distributing its cost, Journal of Economic Theory 57, 125-140.

Janssen, M., Holahan, R., Lee, A., Ostrom E. (2010). Lab Experiments for the Study of SocialEcological Systems. Science 328 (5978), 613-17.

Laffont, J.J. (1987). Incentives and the allocation of public goods. In the Handbook of Public Economics, Vol. 2, 537-69, eds. A. J. Auerbach and M. Feldstein, Amsterdam: North-Holland.

Ledyard, J. O., (1995). Public goods: a survey of experimental research. In the Handbook of Experimental Economics 2, 111-194, eds: Kagel J., and A. Roth, Princeton University Press, Princeton, New Jersey.

Markussen, T., Putterman, L., Tyran, J-R. (2014) Self-Organization for Collective Action: An Experimental Study of Voting on Sanction Regimes. Review of Economic Studies 81 (1), 301324.

Masclet, D., Noussair, C., Tucker, S., Villeval, M.C. (2003). Monetary and Non-Monetary Punishment in the Voluntary Contributions Mechanism. American Economic Review 93 (1), 366-380.

Myerson, R. B. (2008). Mechanism design. The New Palgrave Dictionary of Economics. Second Edition. Eds. S. N. Durlauf and L. E. Blume. Palgrave, Macmillan.

Nikiforakis, N. (2008) Punishment and counter-punishment in public good games: Can we really govern ourselves? Journal of Public Economics 92 (1-2), 91-112.

Nikiforakis, N., Noussair, C.N., Wilkening, T. (2012). Normative Conflict and Feuds: The Limits of Self-Enforcement. Journal of Public Economics 96 (9-10), 797-807.

Noussair, C.N., Tan, F. (2011) Voting on punishment systems within a heterogeneous group. Journal of Public Economic Theory 13 (5), 661-693. 
Okun, A.M (1975). Equality and efficiency: The big tradeoff. Brookings Institution, Washington D.C.

Ostrom, E., Walker, J., Gardner, R. (1992). Covenants with and without a sword: self-governance is possible. American Political Science Review 86(2), 404-417.

Ostrom, E. (2012). Experiments Combining Communication with Punishment Options Demonstrate How Individuals Can Overcome Social Dilemmas. Behavioral and Brain Sciences 35(1), 33-34.

Rand, D.G., Dreber, A., Ellingsen, T., Fudenberg, D., Nowak, M.A. (2009). Positive interactions promote public cooperation. Science 325 (5945), 1272-1275.

Reuben E., Riedl, A. (2009). Public goods provision and sanctioning in privileged groups. Journal of Conflict Resolution 53: 72-93.

Reuben, E., Riedl, A. (2013). Enforcement of Contribution Norms in Public Good Games with Heterogeneous Populations. Games and Economic Behavior 77, 122-137.

Rockenbach, B., Milinski (2006). The efficient interaction of indirect reciprocity and costly punishment. Nature 444, 718-723.

Sally, D. (1995). Conversation and cooperation in social dilemmas: a meta-analysis of experiments from 1958 to 1992. Rationality and Society 7, 58-92.

Samuelson, P.A. (1954). The pure theory of public expenditure. Review of Economics and Statistics $36(4), 387-389$.

Sefton, M., Shupp, R., Walker, J.M. (2007). The effect of rewards and sanctions in provision of public goods. Economic Inquiry 45 (4), 671-690.

Sutter, M., Haigner, S., Kocher, M.G. (2010). Choosing the Carrot or the Stick? Endogenous Institutional Choice in Social Dilemma Situations. Review of Economic Studies 77 (4), 15401566

Tan, F. (2008). Punishment in a linear public good game with productivity heterogeneity. De Economist 156 (3), 269-293.

Varian, H.R. (1994). Sequential provision of public goods. Journal of Public Economics 53, 165 186.

Yamagishi, T. (1986). The provision of a sanctioning system as a public good. Journal of Personality and Social Psychology 51 (1), 110-116.

Young, H.P., 1998. Conventional contracts. Review of Economic Studies 65, 773-792.

Zelmer J. (2003). Linear Public Goods Experiments : A Meta-Analysis. Experimental Economics 6, 299-310.

Weng, Q., Carlsson, F. (2015). Cooperation in teams: The role of identity, punishment, and endowment distribution. Journal of Public Economics 126, 25-38.

World Bank (2010). Integrating development into a global climate regime. 


\section{ONLINE SUPPLEMENTARY MATERIAL}

\section{APPENDIX 1. Instructions for the Het-C treatment (translated from French)}

\section{General information}

You are now taking part in an experiment in economics. Your earnings depend on your decisions and the decisions of other participants. It is therefore important that you read the following instructions carefully. The instructions which we have distributed to you are for your private information. Please do not communicate with the other participants during the experiment.

During the experiment we shall not speak of Euro, but of Experimental Currency Units (ECU). Your entire earnings will be calculated in ECUs. At the end of the experiment the total amount of ECUs you have earned will be converted to Euro at the rate of $\mathbf{1 0}$ ECU $=\mathbf{2 5}$ cents and will be immediately paid to you in cash. In addition, we will give you a one-off payment for showing up on time of $€ 5$. All payments will be made in private by somebody who is not aware of the content of the experiment and none of the other participants will ever know how much you earned in the experiment.

The experiment is divided into two parts. Here, we explain the first part of the experiment. Once the first part is finished you will receive detailed information about the second part of the experiment.

\section{The task}

\section{Part 1}

In the first part, all participants will perform an encoding task. The task is the same for everyone. You will be presented with a set of letters that form "words" with no specific meaning and your task will be to encode these letters by substituting them with numbers using the Table located permanently at the top of your computer screen, as seen in Figure 1.

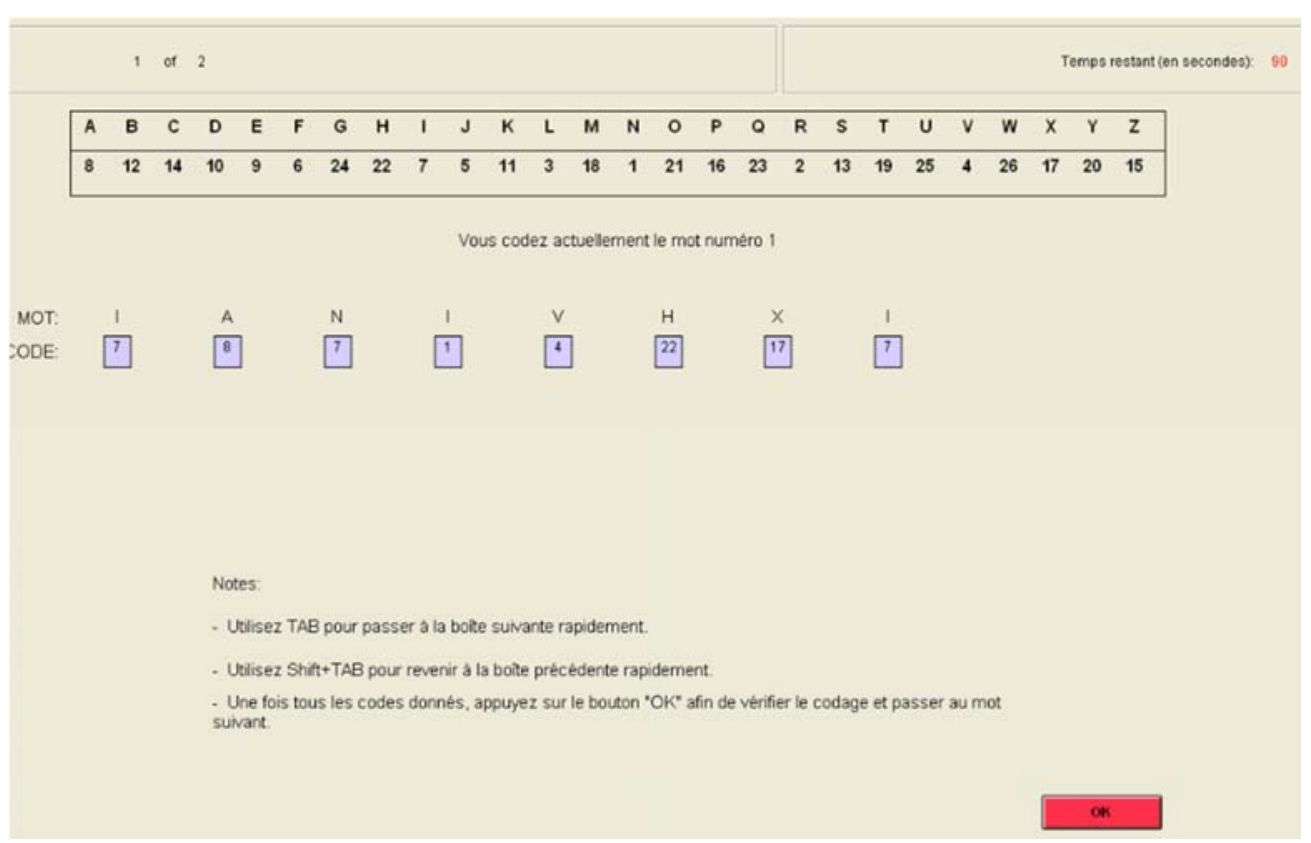

Figure 1. Example of task on the screen 
Example: You are given the word LFAT. The Table shows that $\mathrm{L}=3, \mathrm{~F}=6, \mathrm{~A}=8$, and $\mathrm{T}=19$.

Once you encode a word correctly, the computer will prompt you with another word to encode. Once you encode that word, you will be given another word and so on. This process will continue for 10 minutes. All group members will be given the same words to encode in the same sequence.

\section{The purpose of the task}

The relative performance of each individual in the task will influence the maximum amount they can earn in the second part of the experiment. This will happen in the following way. In the second part, participants will be divided into groups of six. You will therefore be in a group with five other participants. Each group member will be given an endowment (20 ECU) and will be asked to divide it between two accounts. There will be two types of participants in each group. We will refer to them as "Type A" and "Type B". Of the six individuals in each group, three will be of type A and three of type B.

The difference between the two types of participants is the return they get from accounts in which they put their endowment. In particular, Type A participants will obtain a higher return than Type B participants. Information about the exact returns will be given in the second part.

\section{Relative Performance in Part 1 and Type Allocation}

The allocation of types depends on the relative performance of each person in the task compared with that of the other participants in this session. At the end of the Part 1, the computer will rank the participants based on the number of words they encoded. The top $50 \%$ of the individuals in the session will be assigned the role of Type A participants. The bottom $50 \%$ of the individuals will be assigned the role of Type B participants. If two or more participants tie, the computer will determine their type randomly.

You will be informed as to whether you are of Type A or Type B at the beginning of Part 2 of the experiment. Your type will remain the same throughout the session. You will not be informed about the precise number of words encoded by each of your group members until the end of the experiment. At that time, this will be done using a table indicating the number of words decoded by each member of your group.

Please read again these instructions. If you have any question, we will answer your questions in private.

\section{Control Questions}

Please answer the following questions. If you have any questions or have answered all questions, please raise your hand and one of the experimenters will come to you.

1. What does the task in the first part determine?

2. Consider the following example. Assume that there are twelve participants in the session. The following Table indicates the number of words decoded by each participant (These numbers are just an example and should not be taken as an indication about the number of words to encode.) 


\begin{tabular}{|l|c|l|c|}
\hline Participant ID & Number of words & Participant ID & Number of words \\
\hline Participant 1 & 5 & Participant 7 & 20 \\
Participant 2 & 10 & Participant 8 & 8 \\
Participant 3 & 12 & Participant 9 & 6 \\
Participant 4 & 7 & Participant 10 & 22 \\
Participant 5 & 9 & Participant 11 & 10 \\
Participant 6 & 15 & Participant 12 & 4 \\
\hline
\end{tabular}

In the boxes below tick the participant(s) who will be assigned the role of a Type-A participant in part 2 .

\begin{tabular}{|l|l|}
\hline$\square$ Participant 1 & $\square$ Participant 7 \\
$\square$ Participant 2 & $\square$ Participant 8 \\
$\square$ Participant 3 & $\square$ Participant 9 \\
$\square$ Participant 4 & $\square$ Participant 10 \\
$\square$ Participant 5 & $\square$ Participant 11 \\
$\square$ Participant 6 & $\square$ Participant 12 \\
\hline
\end{tabular}

3. Please state whether the following sentences are true or false.

a. Type-A participants will have a higher return from the account in Part 2.

$$
\square \text { True } \quad \square \text { False }
$$

b. Type-B participants will have a higher return from the account in Part 2

$$
\square \text { True } \quad \square \text { False }
$$

\section{Part 2}

This part of the experiment will consist of 20 periods. Your final gain in this experiment will be the sum of your gains in each of these 20 periods. At the start of this part of the experiment, you will be randomly divided into groups of six. You will therefore be in a group with 5 other participants. The composition of each group will remain the same throughout the experiment.

In the beginning of each period, each participant in your group will be randomly assigned a number for identification (i.e. Participant 1, Participant 2, Participant 3, Participant 4, Participant 5, and Participant 6). Identification numbers will be randomly re-assigned in every period. For example, an individual who is Participant 2 in the 1st period, might be Participant 1 in the 2nd period, Player 4 in the 3 rd period and so on. This means that although the participants in your group will remain the same throughout the experiment, you will not be able to link the actions of any given participant across periods. Once the experiment is over, the identities of each participant will be kept anonymous.

Based on the number of words that you and the members of your group encoded in Part 1, you have been assigned the role of either a "Type A" or a "Type B" participant. At the beginning of Part 2, the computer will inform you about your type: Type A or Type B. Your type will remain the same throughout the 
experiment and will influence the return that you receive from the public account as explained below. Each of the groups will have three Type A and three Type B participants.

Once the experiment is over, you will be paid in private and at no point will your group or participant number be revealed. No one will know who was in their group or what actions were carried out by each individual.

Each of the 20 periods is divided into two stages. Below we discuss the two stages in detail.

\section{First Stage}

At the beginning of each of the 20 periods, each participant will receive 20 ECU. In the following, we shall refer to this amount as the "endowment". Your task in the first stage is to decide how to use your endowment. You have to decide how many of the 20 ECU you want to allocate to a public account (from 0 to 20) and how many of them to keep for yourself. You will be able to make your decision by using a screen as the one in Figure 2 (shown for a participant of Type A). The consequences of your decision are explained in detail on the next page.

Once all the group members will have chosen their allocation to the public account, you will be informed about each group member's type and allocation to the public account, your income from the public account and your payoff in this period through a screen as the one seen in Figure 3.

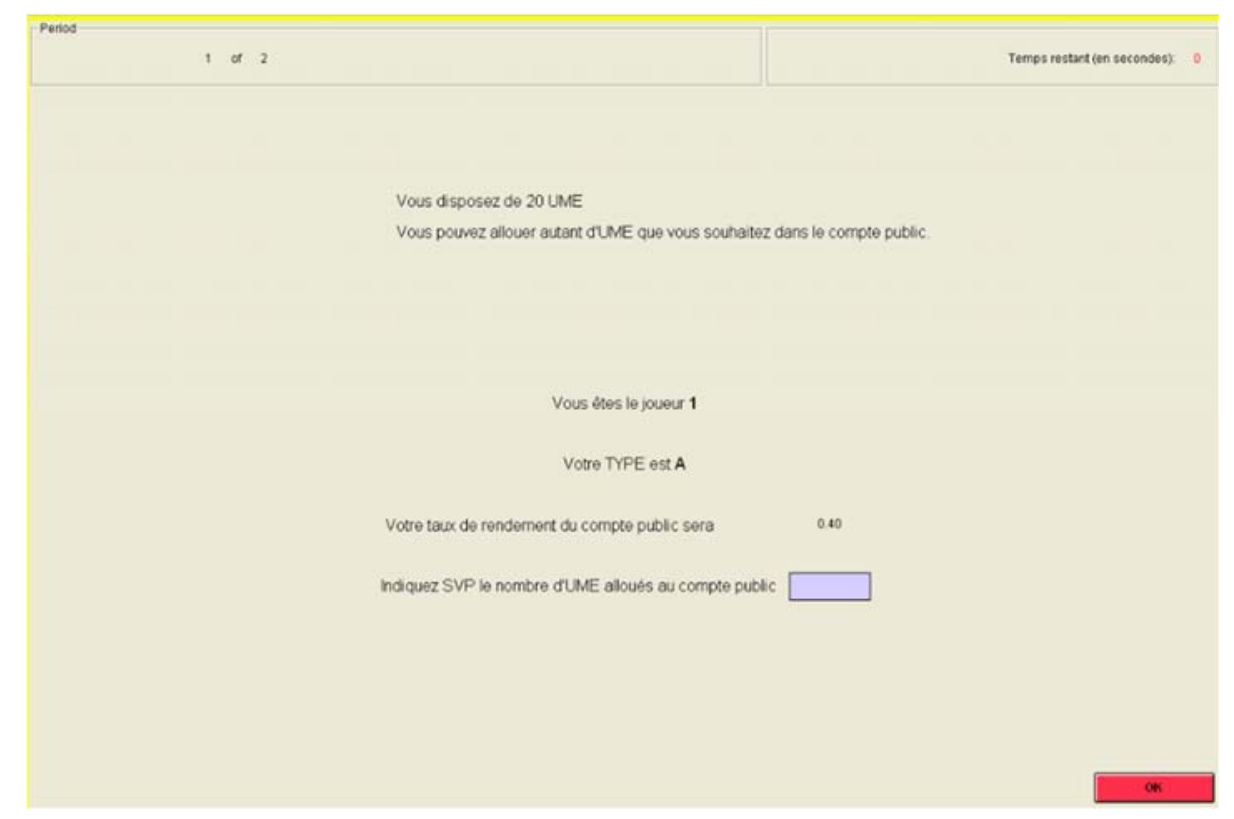

Figure 2. Example of screen-shot in the first stage ( Type A participant) 


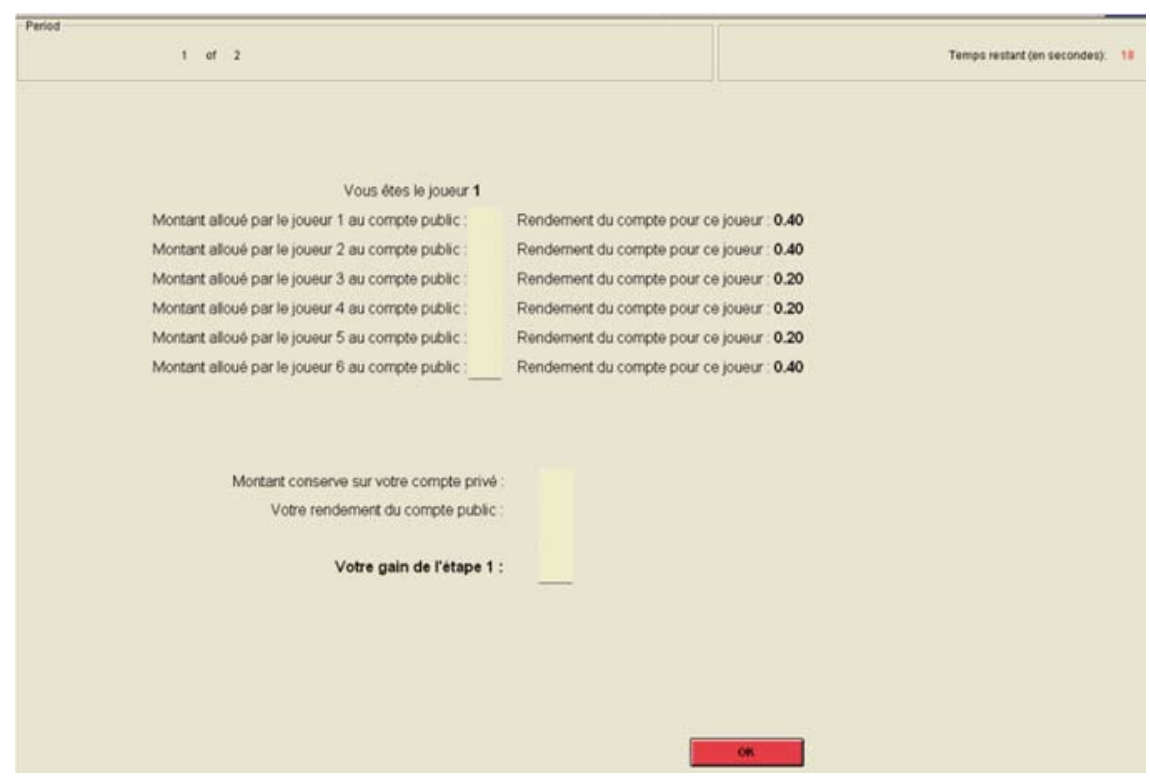

Figure 3. Example of screen-shot with feedback at the end of the first stage

Your earnings for the first stage are calculated using a formula that differs based on whether you are a TypeA participant or a Type-B participant.

The earnings of a Type-A participant are calculated using the following formula (If you have any difficulties understanding these formulas do not hesitate to ask us.)

Earnings at stage $1=$ Endowment of ECU - your allocation to the public account + $0.4 *$ Total allocation to the public account

The earnings of a Type-B participant are calculated using the following formula:

Earnings at stage $1=$ Endowment of ECU - your allocation to the public account + $0.2 *$ Total allocation to the public account

This formula shows that your earnings at the end of the first stage consist of two parts:

1) The ECU which you have kept for yourself (endowment - allocation)

2) The income from the public account, which equals $40 \%$ of the group's total allocation if you are of Type A and $20 \%$ of group's total allocations if you are of Type B.

\section{Example:}

Suppose the sum of the allocations of all group members is 90 ECU.

In this case, a Type-A member of the group receives an income from the public account of:

$0.4 * 90=36$ ECU. A Type-B member of the group receives an income from the public account of: $0.2 * 90$ $=18 \mathrm{ECU}$.

If the total allocation to the public account is 15 points, then Type-A members receive $0.4 * 15=6 \mathrm{ECU}$ from the public account while Type-B members receive $0.2 * 15=3 \mathrm{ECU}$ from the public account. 
You always have the option of keeping the ECU for yourself or allocating them to the public account. Each ECU that you keep raises your end of period income by 1 ECU. Supposing you allocated this point to the public account instead, then the total allocation to the public account would rise by 1 ECU. Your income from the public account would thus rise by $0.4 * 1=0.4$ ECU if you are a Type-A member and $0.2 * 1=0.2$ ECU if you are a Type-B member. However, the income of the other group members would also rise by 0.4 or $0.2 \mathrm{ECU}$ each, so that the total income of the group from the public account would be increased by $3 * 0.4+3 * 0.2=1.8 \mathrm{ECU}$. Your allocation to the public account therefore also raises the income of the other group members. On the other hand, you also earn an income for each ECU allocated by the other members to the public account. In particular, for each ECU allocated by any member you earn either 0.2 or $0.4 \mathrm{ECU}$ depending on your type.

\section{Communication}

In certain periods, you will have the possibility to exchange messages with the other members of your group, before choosing the number of ECU you would like to allocate to the public account.

A dialogue box will appear on the screen in which you will be able to type your messages, as shown in Figure 4. In order to send your message, press the "ENTER" key.

During your messages exchange with the others, please follow two simple rules: 1) remain respectful and do not write rude words, 2) do not identify yourself.

All other group members will be able to read your messages. The id of the participant in the current period will appear next to each message.

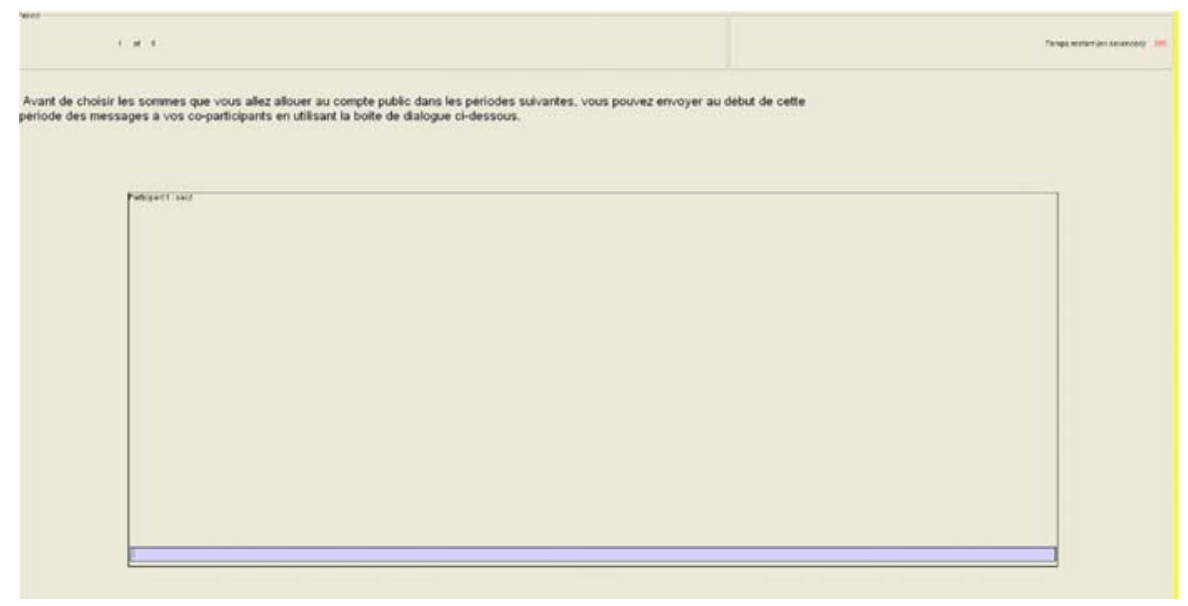

Figure 4. Example of screen-shot with communication

The duration of the communication varies according to the period, as indicated below:

Period 1: 5 minutes

Period 6: 5 minutes

Period 11: 3 minutes

Period 16: 3 minutes.

During this time, you can send as many messages as you want. During other periods you will not be able to exchange messages. 


\section{Second Stage}

In the second stage of each period, you will be informed about how much each group member of each Type allocated individually to the public account in the first stage. In this stage you can increase or leave unchanged the earnings of each member of your group by distributing addition points. The other group members can also increase your income if they wish to.

You will have to decide how many addition points to assign to each of the other five group members. You must enter a number for each of them. If you do not wish to change the earnings of a specific group member, then you must enter 0 . You will be invited to confirm your decisions by entering again these numbers.

Figure 5 below gives an example of a screenshot of decisions in stage 2.

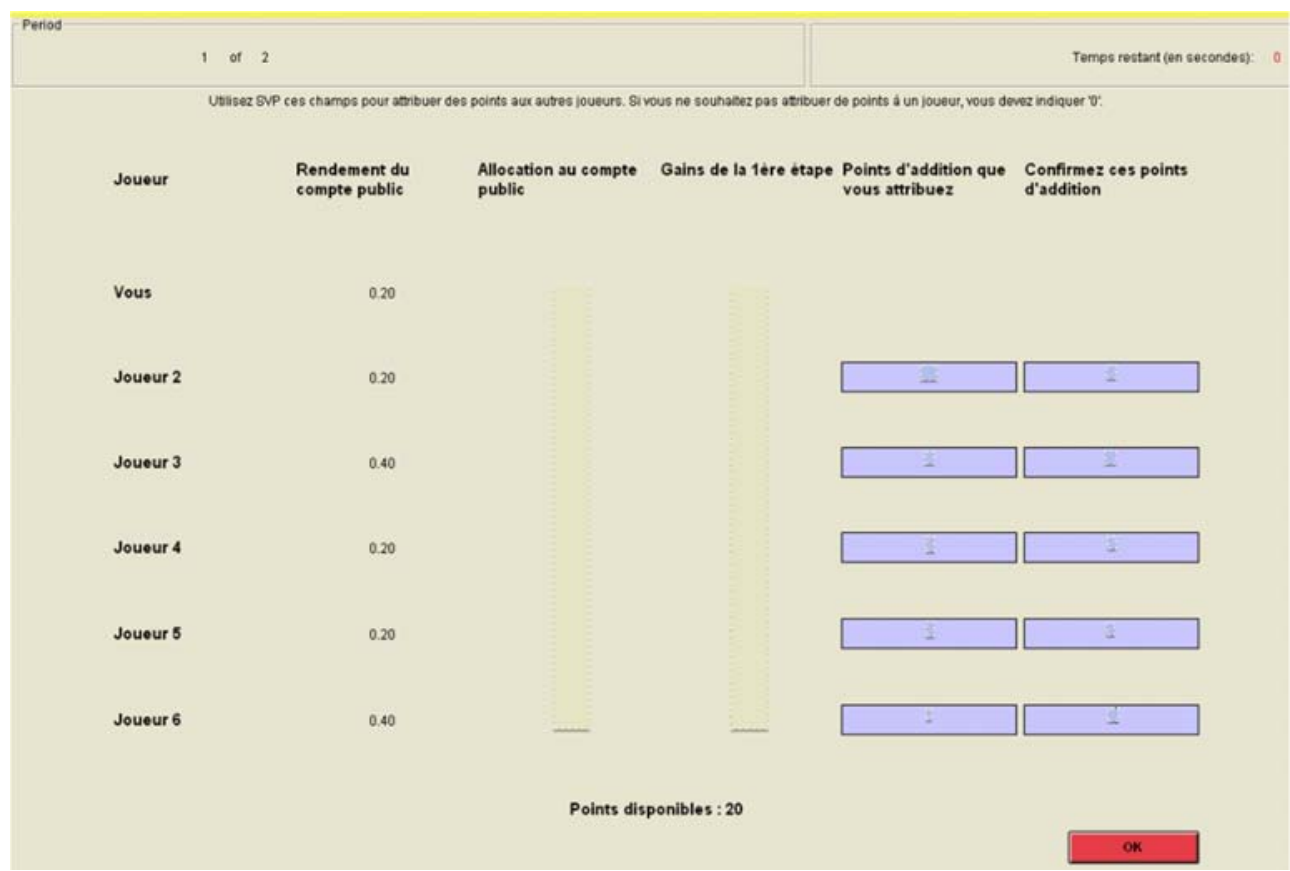

Figure 5. Example of a screenshot of decisions in stage 2

Assigning addition points is costly. Every addition point you assign costs you 0.50 ECU. For example, if you assign 2 addition points to another member, this costs you $1 \mathrm{ECU}$; if, in addition, you assign 4 addition points to another member this costs you an additional $2 \mathrm{ECU}$. In total for this example you have assigned 6 points and your total costs therefore amount to $3 \mathrm{ECU}$.

Costs of assigned addition points $=0.50 \mathrm{ECU} \times$ total number of addition points you have assigned

You can assign a maximum of 20 points in total to the other group members. Within this limit, you may distribute as many points as you wish to a given participant. However, the gain of the total number of points assigned by all group members to a given participant cannot exceed that participant's endowment of 20 ECU.

If you assign 0 addition point to a particular group member, you will not modify his or her earnings. If you assign 1 addition point to a group member, you will increase the earnings of this group member by $1.5 \mathrm{ECU}$. 
If you assign a group member 2 addition points, you will increase the group member's earnings by 3 ECU, and so on. Each addition point that you assign to another group member will increase his or her earnings by 1.5 ECU. Similarly, each addition point assigned to you by another group member will increase your allocation stage earnings by $1.5 \mathrm{ECU}$.

Earnings of received addition points $=1.5 \mathrm{ECU} x$ total number of addition points you have received

Your total earnings from the two stages are therefore calculated as follows:

Total earnings (in ECU) at the end of the second stage $=$ Earnings from the $1^{\text {st }}$ stage $+1.5 *$ (total number of addition points you have received) $-0.50 *$ (total number of addition points you have assigned)

If the value of points that you receive exceeds your initial endowment of $20 \mathrm{ECU}$, the points in excess assigned by the other participants cannot increase your earnings any more. The value of the points exceeding your initial endowment will not be counted in determining your earnings from the period.

After all participants have made their decision, the summary of decisions from the period as well as the associated payoffs will be displayed on a screen such as the one shown in figure 6 .

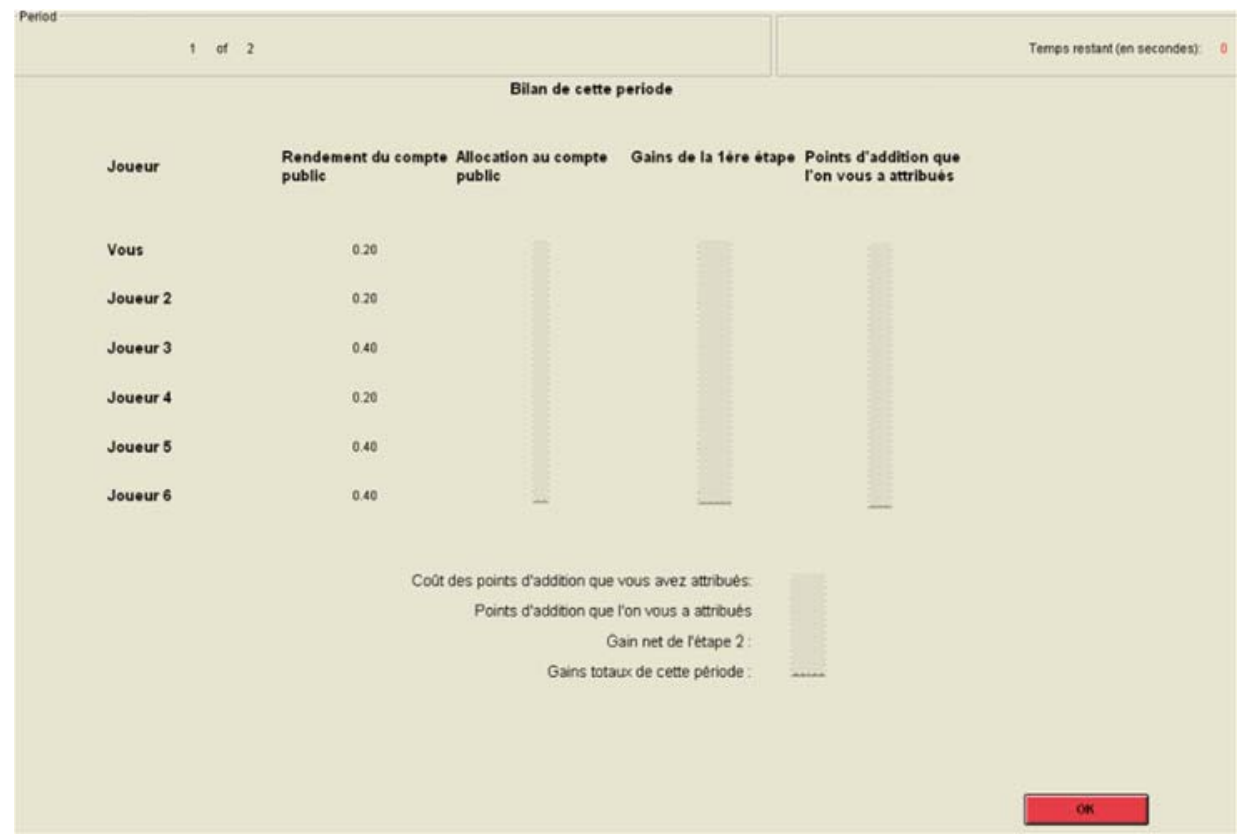

Figure 6. Example of screenshot with information at the end of the period

After you have viewed the earnings screen the period is over and the next period starts automatically. Please read these instructions again. If you have any further questions please raise your hand and one of the experimenters will come to help you. Otherwise, please answer the control questions. 


\section{Control Questions}

Please answer the following questions:

1. Each group member has an endowment of 20 ECU. If nobody (including you) allocates any ECU to the public account. What are:

a. The earnings of Type-A participants after the first stage?

b. The earnings of Type-B participants after the first stage?

2. Each group member has an endowment of $20 \mathrm{ECU}$. You allocate $20 \mathrm{ECU}$ to the public account. All other group members allocate $20 \mathrm{ECU}$ each to the public account. Suppose that you are a participant of Type-A. What are:

a. Your earnings after the first stage?

b. The earnings of the other Type-A group members?.........

c. The earnings of the Type-B group members?

3. Each group member has an endowment of 20 ECU. Suppose you and the other Type-A participants allocate $20 \mathrm{ECU}$ each to the public account and the three Type-B participants allocate $5 \mathrm{ECU}$ each to the public account. What are:

a. Your earnings after the first stage?

b. The earnings of the other Type-A group members?.........

c. The earnings of the Type-B group members?

4. Each group member has an endowment of $20 \mathrm{ECU}$. The other five group members allocate together a total of 30 ECU to the public account. Suppose that you are a participant of Type-A. What are:

a. Your earnings after the first stage if you allocate $0 \mathrm{ECU}$ to the public account?

b. Your earnings at the end of the first stage if you allocate $15 \mathrm{ECU}$ to the public account?

5. Each group member has an endowment of 20 ECU. You allocate 8 ECU to the public account. Suppose that you are a participant of Type-B. What are:

a. Your earnings after the first stage if the other group members together allocate a further total of 7 ECU to the public account?

b. Your earnings at the end of the first stage if the other group members together allocate a further total of $22 \mathrm{ECU}$ to the public account?

6. Your earnings from the first stage are 22 ECU. How much will your earnings at the end of the second stage be if:

a. You receive 2 points, but do not assign any yourself?

b. You receive 2 points and assign 4 points to a group member?

7. Please indicate whether the following statements are true or false:

a. Each participant keeps the same type (A or B) throughout the 20 periods.

$\square$ True $\quad \square$ False

b. Each participant keeps the same id number $(1,2,3,4,5$ or 6$)$ throughout the 20 periods.

$\square$ True $\quad \square$ False 


\section{APPENDIX 2 - Comparison across the two variants of communication in HET-C}

In figures A1 and A2, HET-C pools the data of the two variants of the HET-C treatment: in one variant subjects could only send messages to everyone (HET-C Public); in the second variant, subjects could send both messages to everyone and 'private messages' to the group members with the same return as them (HETC Public-Private). As can be seen, the aggregate patterns across the two conditions are remarkably similar.

Figure A1 - Mean contributions across treatments

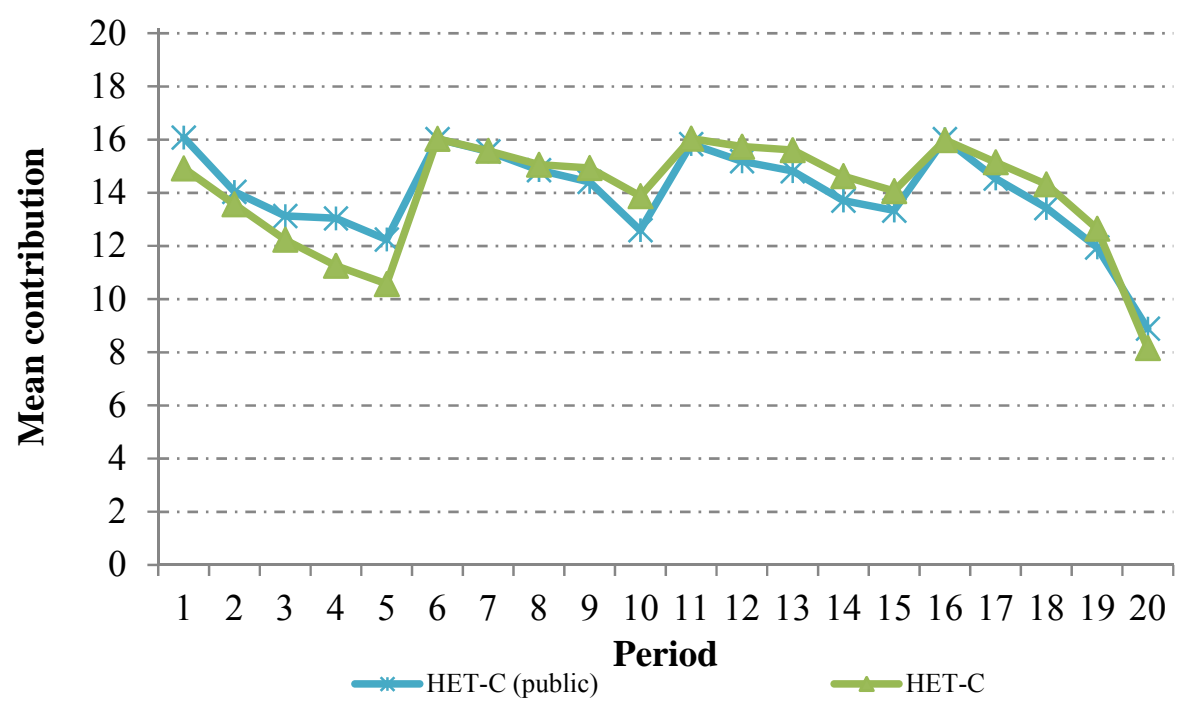

Figure A2 - Mean earnings across treatments

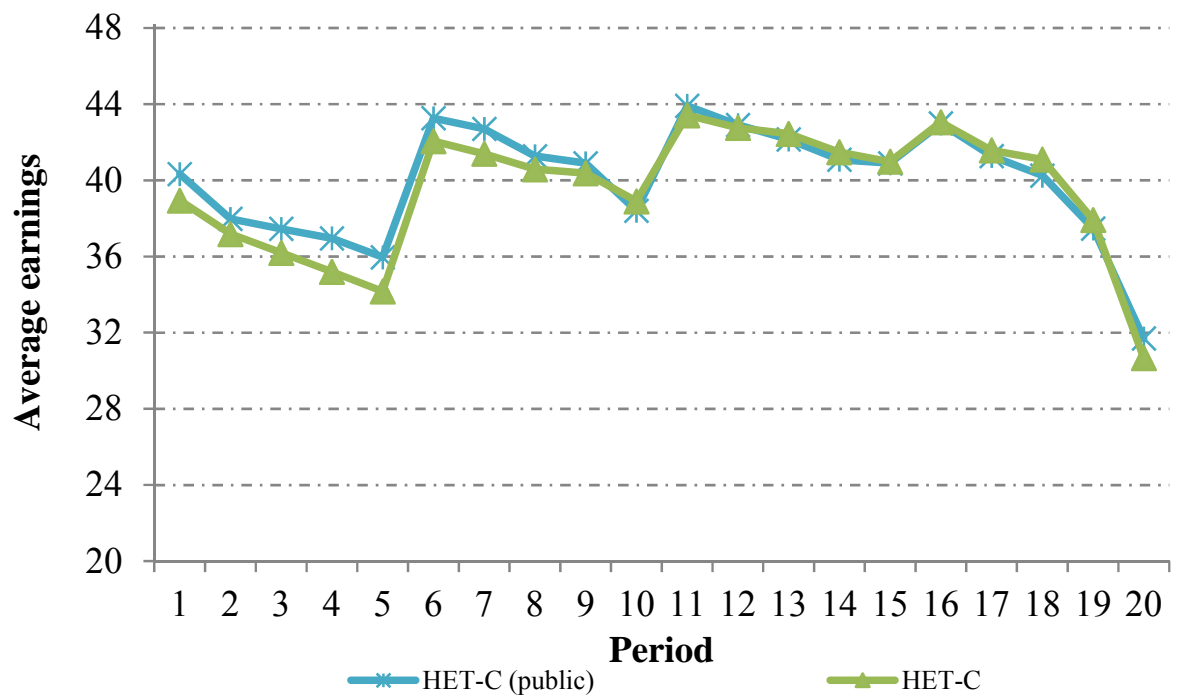


In Table A1, we compare the mean contributions and mean final earnings in the two variants of the HET-C treatment. Non parametric tests indicate minor difference between these two variants in contribution behavior which are far from being statistically significant. The only significant difference is found for the low return subjects' total earnings.

Table A1 - Summary statistics on contributions and final earnings in the two variants of the HETC treatment

\begin{tabular}{lcccc}
\hline \hline Treatments & $\begin{array}{c}\text { All } \\
\text { subjects }\end{array}$ & $\begin{array}{c}\text { High-return } \\
\text { subjects }\end{array}$ & $\begin{array}{c}\text { Low-return } \\
\text { subjects }\end{array}$ & $\begin{array}{c}\text { Ratio } \\
\mathrm{H} / \mathrm{L}\end{array}$ \\
\hline Mean contributions & $13.98(7.66)$ & $17.57(6.28)$ & $10.40(7.23)^{* *}$ & 1.69 \\
HET-C Public (1) & & $16.94(6.07)$ & $11.17(7.29)^{* *}$ & 1.52 \\
HET-C Public-Private (2) & $14.06(7.30)$ & $p=0.335$ & $p=0.847$ & \\
(1) vs. (2) & $p=0.847$ & & & \\
\hline Mean final earnings & & & & \\
HET-C Public (3) & $39.99(10.16)$ & $44.04(10.94)$ & $35.95(7.37)^{* *}$ & 1.22 \\
HET-C Public-Private (4) & $38.98(11.94)$ & $45.36(11.04)$ & $32.61(9.06)^{* *}$ & 1.39 \\
(3) vs. (4) & $p=0.630$ & $p=0.700$ & $p=0.043$ & \\
\hline
\end{tabular}

Note: Standard deviations in parentheses. Comparisons between conditions ((1) vs. (2) and (3) vs. (4)) report the p-values of Mann-Whitney tests in which each group averaged over all periods gives one independent observation ( $\mathrm{N}=9$ in HET-C Public and $\mathrm{N}=8$ in HET-C Public-Private). In the column "Low-return subjects", ** indicate significance at the $5 \%$ level in Wilcoxon tests comparing contributions and earnings relative to low-return vs. highreturn subjects. 


\section{APPENDIX 3 - Analysis of communication in HET-C}

We asked three independent coders who were blind to our research hypotheses to code the content of messages exchanged between subjects in treatment HET-C. Then, we requested two additional coders to check the consistency between the initial classification of messages. We present the results from this exercise in this appendix. In summary, this analysis supports the conclusions concerning group contribution norms in Section 3.2.

Table A2 below complements Table 4 by reporting information on the content of messages for each group category, where each group in each period with communication provides one observation. Columns (1) to (3) report the percentage of observations relating to the efficient contribution rule, the equality of earnings rule, and other contribution rules, respectively. Column (4) indicates the percentage of observations in which conversations in a period evoke more than one contribution rule and column (5) reports the percentage of observations in which rewards are evoked as a solution to compensate low-return players from the inequality deriving from the first stage of the game. Columns (6) and (7) report the mean responses to a post-experiment survey about the appeal of different contribution rules. ${ }^{18}$ Finally, columns (8) and (9) report the mean responses to the post-experiment survey about the player's motivation when assigning reward points. ${ }^{19}$

Table A2 indicates that the content of conversations differs strongly across groups. Column (1) indicates that the rule prescribing equal contributions is evoked in only $20.83 \%$ of the observations when groups behave according to the equality-over-efficiency rule, compared to $62.50 \%$ in groups behaving according to the efficiency-over-equality rule and $71.43 \%$ in groups following other rules. Conversely, column (2) shows that the rule of equal earnings is evoked in $79.17 \%, 6.25 \%$ and $17.86 \%$ of the corresponding observations. Table A2 also indicates that members of groups adopting the equality-overefficiency contribution rule are significantly more likely than members of other groups to agree with the statement that group members should earn the same regardless of their type (column (6)); conversely, members of groups favoring the efficiency-over-equality rule are significantly more likely than members of other groups to agree with the statement that group members should contribute the same regardless of their type (column (7)).

The entries in column (5) indicate that discussions about using rewards as a mean for compensating low-return players for the inequality deriving from the first stage of the game occur very rarely, regardless of the contribution rule adopted by the groups. Most discussions about rewards focus on how many points to assign. The post-experiment survey is also informative. Players from groups who prioritize equality are significantly more likely than the players from the other group categories to report that they assigned points to ensure that earnings of all players would be more or less the same (column (8)). A Wilcoxon test indicates that these players are also significantly more likely to report this reason for assigning points than the willingness to reward those who allocated more ECU to the public account than the others.

\footnotetext{
${ }^{18}$ For the equal-earnings rules, using a scale ranging from 1 ("I fully disagree") to 7 ("I fully agree"), we asked subjects to tell us the extent to which they agree with the statement "Ideally, all group members should earn more or less the same from the experiment irrespective of whether they are of type A [i.e., high-return] or B [i.e., low-return]". For the equal-contributions rule (which is consistent with efficiency), we asked them to tell us the extent to which they agree with the statement "Ideally, all group members should allocate the same number of ECU to the public account irrespective of whether they are of type A or B and thus earn different amounts".

${ }^{19}$ Using also a scale ranging from 1 ("I fully disagree") to 7 ("I fully agree"), subjects who assigned points had to assess the following two statements: "I assigned points to ensure that earnings of all players will be more or less the same" and "I assigned points to reward those who allocated more ECU to the public account than the others".
} 
Table A2 - Group-level analysis of communication within a period (HET-C treatment)

\begin{tabular}{|c|c|c|c|c|c|c|c|c|c|}
\hline \multirow[t]{2}{*}{ Categories of groups } & \multicolumn{3}{|c|}{ Rules discussed in a period } & \multirow[b]{2}{*}{$\begin{array}{c}\text { Multiple } \\
\text { rules } \\
\text { discussed } \\
\text { in a period } \\
(4)\end{array}$} & \multirow[b]{2}{*}{$\begin{array}{l}\text { Rewards as } \\
\text { compensation } \\
\text { in a period } \\
\text { (5) }\end{array}$} & \multicolumn{4}{|c|}{ Post-experimental questionnaire (scale 1 to 7 ) } \\
\hline & $\begin{array}{c}\text { Efficient } \\
\text { contributio } \\
\mathrm{n} \\
\text { (1) }\end{array}$ & $\begin{array}{c}\text { Equal } \\
\text { earnings } \\
(2)\end{array}$ & $\begin{array}{l}\text { Other } \\
\text { (3) }\end{array}$ & & & $\begin{array}{l}\text { Members } \\
\text { should } \\
\text { earn the } \\
\text { same } \\
(6)\end{array}$ & $\begin{array}{c}\text { Members } \\
\text { should } \\
\text { contribute the } \\
\text { same (7) }\end{array}$ & $\begin{array}{l}\text { Rewards to } \\
\text { equalize } \\
\text { earnings } \\
\text { (8) }\end{array}$ & $\begin{array}{l}\text { Rewards to } \\
\text { reciprocate } \\
\text { high } \\
\text { contrib. } \\
\text { (9) }\end{array}$ \\
\hline $\begin{array}{l}\text { Equality over } \\
\text { efficiency } \mathrm{N}=6(\mathrm{~A}) \\
(4,5,9,11,13,14)\end{array}$ & $\begin{array}{l}20.83 \% \\
(41.49)\end{array}$ & $\begin{array}{c}79.17 \% * * \\
(41.49)\end{array}$ & $\begin{array}{c}16.67 \%{ }^{\mathrm{ns}} \\
(38.07)\end{array}$ & $\begin{array}{l}29.17 \% \\
(46.43)\end{array}$ & $\begin{array}{c}8.33 \% \\
(28.23)\end{array}$ & $\begin{array}{c}6.06 \\
(1.57)\end{array}$ & $\begin{array}{c}2.61 * * \\
(2.05)\end{array}$ & $\begin{array}{c}5.94 \\
(1.71)\end{array}$ & $\begin{array}{c}2.67 * * \\
(2.27)\end{array}$ \\
\hline $\begin{array}{l}\text { Efficiency over } \\
\text { equality } \mathrm{N}=4(\mathrm{~B}) \\
(3,7,10,17)\end{array}$ & $\begin{array}{c}62.50 \% \\
(50)\end{array}$ & $\begin{array}{c}6.25 \% * \\
(25)\end{array}$ & $\begin{array}{c}6.25 \% * \\
(25)\end{array}$ & $\begin{array}{l}12.50 \% \\
(34.16)\end{array}$ & $\begin{array}{l}12.50 \% \\
(34.15)\end{array}$ & $\begin{array}{c}4.42 \\
(2.16)\end{array}$ & $\begin{array}{l}5.04^{\mathrm{ns}} \\
(2.27)\end{array}$ & $\begin{array}{c}3.12 \\
(2.23)\end{array}$ & $\begin{array}{l}3.25^{\mathrm{ns}} \\
(2.23)\end{array}$ \\
\hline $\begin{array}{l}\text { Other groups } \mathrm{N}=7 \\
\text { (C) } \\
(1,2,6,8,12,15,16)\end{array}$ & $\begin{array}{c}71.43 \% \\
(46)\end{array}$ & $\begin{array}{c}17.86 \% * * \\
(39)\end{array}$ & $\begin{array}{c}39.29 \% * * \\
(49.73)\end{array}$ & $\begin{array}{l}39.29 \% \\
(49.73)\end{array}$ & $\begin{array}{l}35.71 \% \\
(48.80)\end{array}$ & $\begin{array}{c}4.67 \\
(2.07)\end{array}$ & $\begin{array}{l}4.09^{\mathrm{ns}} \\
(2.29)\end{array}$ & $\begin{array}{c}4.02 \\
(2.12)\end{array}$ & $\begin{array}{l}4.07^{\mathrm{ns}} \\
(2.13)\end{array}$ \\
\hline $\begin{array}{l}\text { (A) } v s .(B) \\
\text { (A) } v s .(C) \\
\text { (B) } v s .(C)\end{array}$ & $\begin{array}{l}p=0.006 \\
p=0.004 \\
p=0.366\end{array}$ & $\begin{array}{l}p=0.008 \\
p=0.007 \\
p=0.506\end{array}$ & $\begin{array}{l}p=0.598 \\
p=0.169 \\
p=0.090\end{array}$ & $\begin{array}{l}p=0.165 \\
p=0.544 \\
p=0.108\end{array}$ & $\begin{array}{l}p=0.617 \\
p=0.414 \\
p=0.679\end{array}$ & $\begin{array}{l}p=0.024 \\
p=0.018 \\
p=0.703\end{array}$ & $\begin{array}{l}p=0.010 \\
p=0.012 \\
p=0.058\end{array}$ & $\begin{array}{l}p=0.010 \\
p=0.012 \\
p=0.254\end{array}$ & $\begin{array}{l}p=0.198 \\
p=0.045 \\
p=0.086\end{array}$ \\
\hline
\end{tabular}

Notes: Columns (1) to (5) report the content of messages where each group in each period with communication gives one observation. Columns (6) to (9) report the mean responses to a post-experiment survey using a scale ranging from 1 ("I fully disagree") to 7 ("I fully agree"). Comparisons between categories of groups ((A) vs. (B), (A) vs. (C), and (B) vs.

(C)) report the p-values of Mann-Whitney tests in which each group gives one independent observation. ** and * indicate significance at the $5 \%$ and $10 \%$ levels, respectively and $n s$ is for no significance in Wilcoxon tests comparing (2) and (3) to the reference (1), comparing (7) to reference (6) and comparing (9) to reference (8). All tests are two-tailed. 